\title{
A Comprehensive Study on Technologies of Tyre Monitoring Systems and Possible Energy Solutions
}

\author{
Ali E. Kubba ${ }^{1, *}$ and Kyle Jiang ${ }^{2}$
}

1 Fusion Innovations Ltd, Research and Innovation Services, Birmingham Research Park, Vincent Drive, Edgbaston, Birmingham, B15 2SQ, UK

2 School of Mechanical Engineering, University of Birmingham, Edgbaston, Birmingham, B15 2TT, UK; E-Mail: k.jiang@bham.ac.uk

* Author to whom correspondence should be addressed; E-Mail: A.E.S.Kubba@bham.ac.uk; Tel.: +44-0121-227-5282; Fax: +44-0121-415-8530.

Received: 31 August 2013; in revised form: 10 May 2014 / Accepted: 15 May 2014 /

Published: 11 June 2014

\begin{abstract}
This article presents an overview on the state of the art of Tyre Pressure Monitoring System related technologies. This includes examining the latest pressure sensing methods and comparing different types of pressure transducers, particularly their power consumption and measuring range. Having the aim of this research to investigate possible means to obtain a tyre condition monitoring system (TCMS) powered by energy harvesting, various approaches of energy harvesting techniques were evaluated to determine which approach is the most applicable for generating energy within the pneumatic tyre domain and under rolling tyre dynamic conditions. This article starts with an historical review of pneumatic tyre development and demonstrates the reasons and explains the need for using a tyre condition monitoring system. Following this, different tyre pressure measurement approaches are compared in order to determine what type of pressure sensor is best to consider in the research proposal plan. Then possible energy harvesting means inside land vehicle pneumatic tyres are reviewed. Following this, state of the art battery-less tyre pressure monitoring systems developed by individual researchers or by world leading tyre manufacturers are presented. Finally conclusions are drawn based on the reviewed documents cited in this article and a research proposal plan is presented.
\end{abstract}

Keywords: TPMS; pressure sensor; energy harvesting means; tyre structure 


\section{Introduction}

This article presents a research proposal plan on developing a functional tyre condition monitoring system (TCMS). The proposed device is planned for land vehicles, but can also be used for aircraft with limited modifications. A TCMS, also called a Tyre Pressure Monitoring System (TPMS), when it is primarily installed to monitor inflation pressure, is an electronic device by which tyre conditions, such as tyre inflation pressure, cavity air temperature, tyre belt stress and strain, normal load, traction force, acceleration, tyre wear, etc., are measured and transmitted to notify the vehicle driver about the values of the measured quantities, the status of the tyre, and to warn the driver if there is any unsafe change in any of the measured values, e.g., low inflation pressure. TCMS is usually installed inside the pneumatic tyre cavity, but it can also be designed to be tightened onto the tyre valve stem cap externally.

Deflated tyres can cause several problems which may lead to insecurity; extra fuel consumption; excessive tyre wear; reduction in tyre lifetime; higher rolling resistance; noise emissions and escalation in $\mathrm{CO}_{2}$ emissions. It is estimated that from the introduction of the TPMS to the EU-15 alone; reduction in $\mathrm{CO}_{2}$ emissions can be 9.6 million tons per year by 2020. On average; it is estimated that maintaining the recommended tyre inflation pressure can reduce $\mathrm{CO}_{2}$ emissions and fuel consumption by about $2.5 \%$. In a passenger car tyre; the recommended inflation pressure lies within 1.9-2.2 bar pressure range. A decrease of 0.5 bar in the recommended inflation tyre pressure may increase that tyre rolling resistance by $10 \%$; leading to an increase in fuel consumption of 2.5\% [1]. According to Transense technologies plc; a company based in Bicester; UK; has developed a SAW based tyre pressure monitoring system which is supposed to be available on the market for motorsport applications [2]; a car that has tyres that are $20 \%$ underinflated has an increased rolling resistance of $12 \%$; reducing tyre lifetime by up to $50 \%$ and leading to increased fuel consumption by $6 \%$ [3]. Existing TPMSs require a power supply; which is nearly always a battery; however; an external power supply is possible; e.g., electromagnetic coupling and/or RF power telemetry. Problems with batteries in TPMSs can be summarised into three main categories; safety issues due to battery finite life; environmental impact consequences primarily due to the disposing of toxic chemicals contained in depleted TPMS batteries (Spectrum Batteries Inc.: Flushear, TX, USA) [4]; and initial and then maintenance costs; the former is due to the need for specially made batteries for the TPMS environment; while the latter results from the need for the depleted batteries replacement. A TPMS battery is subjected to the tyre cavity's harsh environment which can significantly deteriorate its efficiency by the extreme climatic conditions inside the tyre; e.g., a wide operation temperature range and battery contacts' problems resulting from the extreme vibration conditions occurring within the tyre-rim assembly [5]. External TPMS powering; whether via electromagnetic coupling or through an RF powered system; relatively consume a high amount of power (Delta Electronics Inc.; Taipei; Taiwan) [6]; which therefore results in the consuming of more fuel. Furthermore; the reader part of these types of tyre monitoring systems has to be installed within a few centimetres of the sensor embedded inside the tyre. The TCMS developed in this research avoids the energy problem associated with conventional TPMSs by using an energy harvesting technique which converts a fraction of the strain energy dissipated throughout the pneumatic tyre cyclic deformation into electrical charge and stores it in an electrical capacitor in order to use it via the system circuitry. In this way; using batteries for powering the TCMS is eliminated and therefore 
obviates the disposal of a huge amount of depleted batteries; which is a contribution towards eco-driving.

In order to obtain a long life vehicle tyre and to promote road traffic safety, research has been conducted by several researchers and by some of the biggest tyre manufacturers, e.g., Michelin, Continental, Pirelli and Dunlop [7] to produce a means to sustain road traffic safety by improving vehicle control system and tyre-road interaction, e.g., tyre contact patch area and pressure distribution within it, that is an intelligent tyre.

Maintaining tyre pressure levels is particularly vital for avoiding traffic accidents and prevents wasting fuel caused by faulty tyre air pressure levels; which therefore helps the reduction of carbon emissions. In the US, the government has put in to place legislation in which all new vehicles since September 2007, except those with dual wheels on an axle, have to have a TPMS installed in all its tyres. This is enforced by the National Highways and Traffic Safety Administration (NHTSA)-(FMVSS No. 138) [8-15]. Likewise, in the EU from 1st November 2012, all new vehicles must have a TPMS installed (UNECE Vehicle Regulations (Regulation No. 64))[15-17]. The next paragraph explains the problems associated with powering a tyre monitoring system.

The problems associated with using batteries as the main power supply unit in TPMSs include limited life time, low energy density at extreme temperatures [18,19], energy capacity deterioration associated with high centrifugal loading, shocks and vibration exposure, and the need for frequent replacements $[20,21]$. The technique used in the proposed TCMS is a clean and perpetual solution to powering sensors by avoiding the use and the need for the toxic and corrosive thionyl chloride chemistry used in TPMS lithium batteries, and subsequently their resulted waste, in which special handling and disposal is required. However, the designed system is active only when the containing tyre is in motion. This property helps by saving energy from being wasted while the vehicle is stationary and accelerates waking up time after starting off.

In general, a TCMS consists of three main units; the power supply unit, sensing unit, and readout circuitry unit as shown in Figure 1. The power supply unit comprises an energy source element which is primarily a battery, and a power monitoring and conditioning circuitry. The sensing unit includes different types of sensors with respect to the properties intended to be measured, e.g., pressure and temperature sensors. The third unit is a programmable element run by a microcontroller. Its function is summarised into handling the system sensors' input and output signals using an interface circuit, switching on and off the system components, and transmitting the measured quantities [22-24].

The research is planned to address the power requirements and sensing mechanism issues related to the above mentioned three main TCMS units in such a way that an energy harvester is installed on the inner surface tyre linear. In addition, the overall power consumption of the system must be within the energy harvester power generation capacity in order to achieve an acceptable duty cycle. A duty cycle is the fraction of the time over which a device is active divided by the length of a certain period of time.

Figure 2 shows the developed TCMS in this research. The main difference in this system, compared to the general TCMS components, is the power supply unit. This device is self-powered and therefore does not require using a battery or any other means of contact free powering methods, e.g., induction coupling. The research is intended to develop a TCMS that can be attached to the inside of a passenger vehicle pneumatic tyre. Having the system applied on that area allows the sensing of additional 
parameters rather than inflation pressure and tyre cavity air temperature, e.g., traction force, normal load, tyre strain, acceleration, etc. and promotes the intelligent tyre system.

Figure 1. General TCMS schematic diagram.

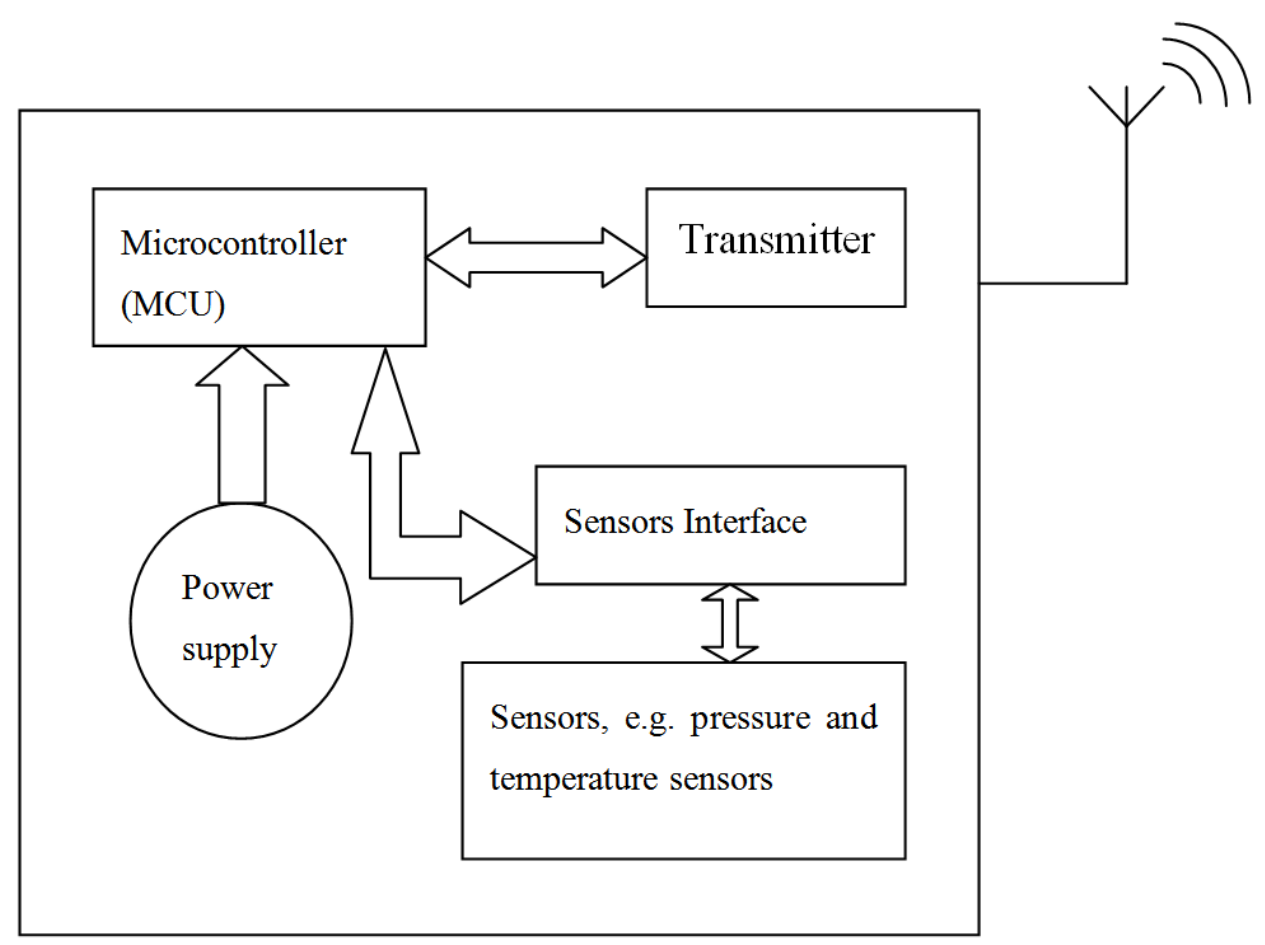

The key feature of the TCMS developed in the research is its energy scavenging capability and wide speed range coverage. Instead of embedding batteries to power sensors and the transmitter, it converts tyre strain energy into electricity using a piezoelectric device. The developed TCMS has the advantages of minimal maintenance requirements, obviating the disposal of large quantities of batteries, and the compatibility of functioning over an automotive temperature range of a higher level than lithium batteries.

The development of the energy harvesting based TCMS went through logical steps as follows. First, a micro tyre pressure sensor and several types of electronic circuits for both power management, and measuring and transmitting the embedded sensors data purposes were designed and tested. Then two energy harvesting units were studied. The harvesting unit of the higher energy density was then selected for pneumatic tyre application. This energy harvesting unit which can operate efficiently in the tyre cavity atmosphere conditions and generates sufficient energy for the TCMS circuitry was promoted by testing its performance via applying it inside a pneumatic tyre and observing its performance under different loading and speed conditions. Experiments were then conducted to examine the performance of the selected Piezo Fibre Composite (PFC) energy harvester in the School of Mechanical Engineering laboratory by using a tyre test rig, in which controlled loading and speed conditions were applied. Then the chosen energy harvester, coupled with the integrated TCMS circuitry including the pressure and temperature sensors, were tested on both the tyre test rig and on the road including motorways to validate the designed TCMS performance and to make it ready for application in passenger vehicle tyres. 
The article structure starts with a historical review of pneumatic tyres and means to measure tyre inflation pressure, followed by a comparison between major pressure sensing techniques. Then possible extractable energies and major energy extraction techniques within rolling tyres are illustrated in detail. A state of the art of useful energy harvesting techniques and ones developed by researchers for powering TPMS is presented. Following that power conditioning and TCMS design principles are explained. Finally conclusions and discussion in order to establish a research plan for designing a TCMS.

Figure 2. TCMS schematic diagram.

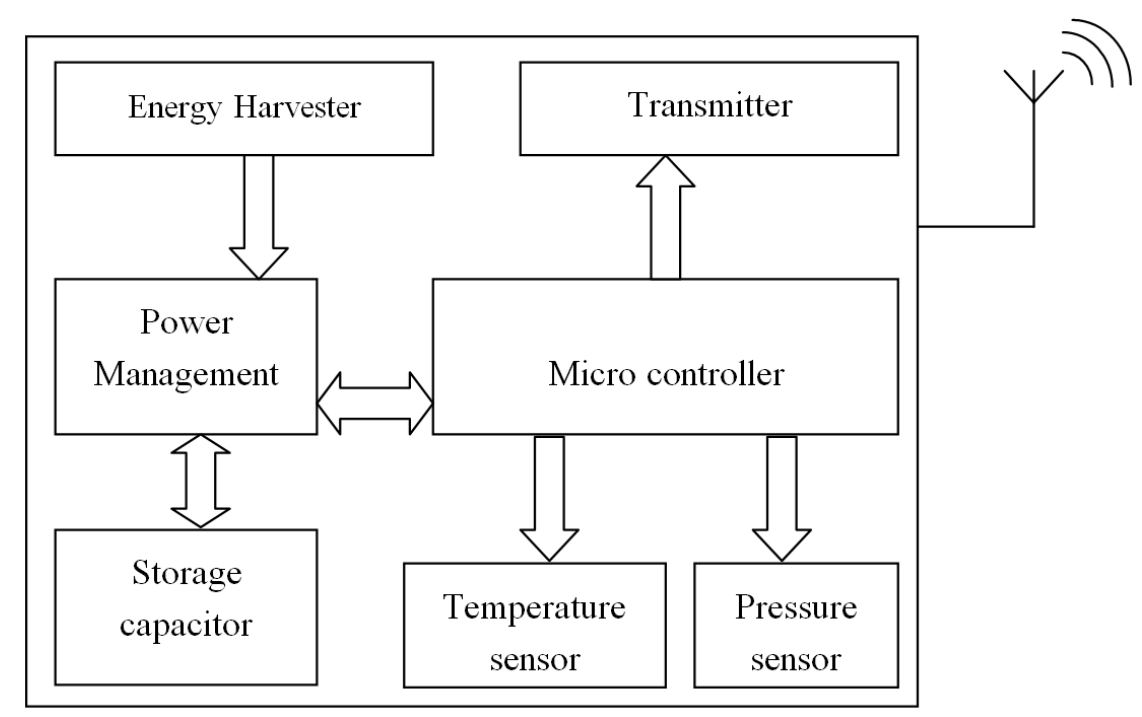

\section{TCMS Design Principles}

The aim of the research proposal plan is to design and develop a competitive battery-free tyre condition monitoring system (TCMS) and to test its feasibility in the laboratory and on the road. The power source is aimed to be a robust and durable energy harvesting unit that can resist tyre cavity conditions and is able to perform up to standard over a wide range of vehicle speeds and loading conditions for the lifetime of the tyre. An additional aim is to design a novel low power micro pressure sensor as a part of the TCMS to reduce the overall system power requirement, particularly when tyre air pressure readings are being taken. It is also intended that the developed TCMS will have a miniature structure suited for installation on the inner tyre surface.

\section{Historical Review}

This section summarises how the pneumatic tyre was developed over history and how different methods have been used to measure tyre inflation pressure.

\subsection{Pneumatic Tyre}

Tyre specification is always a matter of selecting the most appropriate design based on a number of inter-related and often conflicting properties. The first documented invention of the pneumatic tyre was in 1845 by Robert William Thomson, who called the invention the Aerial Wheel. This invention introduced three new advantages of the Aerial Wheel: reduced rolling resistance, better 
manoeuvrability, and decreased noise while in motion. At that time, Thomson first suggested that the new tyre would be inflated with air along with "various solid substances of an elastic quality". A tyre with multiple tubes was first developed. Wired type tyre construction with a straight side rim appeared in 1922 made by Dunlop. Back in 1892, a tubeless tyre was predicted to be the future by W. H. Paull. It took approximately six decades until tubeless tyres became commercially available [25]. The next section summarises the development of air pressure sensors following the discovery of pressure phenomena by Galileo in 1594.

\subsection{Air Pressure Measurement}

Having pneumatic tyres filled with air, makes the air act as an ideal compressible elastic support for the tyre structure and the amount of air needed inside the tyre is directly determined by the vertical load capacity for which the tyre is designed. Friction coefficients, both static and kinetic, are mildly affected by inflation pressure on dry roads, while on wet surfaces inflation pressure is a crucial factor to improve both friction coefficients [26]. Having the correct tyre pressure benefits optimal performances in several land vehicle controls, e.g., braking distance and less tyre wear. It also saves fuel and reduces the possibility of having unexpected tyre break down and overheating, which can be a direct cause of fatal accidents [27,28]. Noise generated from rolling tyres increases when tyres are under low inflation pressure. These facts make measuring tyre air pressure vital and therefore different types of tyre pressure measurement have been developed. A detailed report by W. Reithmaier et al. [29] demonstrates and analyses tyre-related accident research data and summarises the main effects of under inflated tyres on their durability and overall vehicle performance. In addition, this report presents different techniques and methods to monitor, control and maintain tyre inflation pressure.

Mechanical pressure gauges are the most common tyre pressure measurement tool and still the most widely used instrument for measuring pressure of different fluids. Originally they were invented for measuring atmospheric pressure, as the aneroid barometer by Lucien Vidie for low pressure in 1844, and 5 years later developing into the Bourdon tube pressure gauge for high pressures [30-32]. These pressure sensors were the first ones that did not use liquids for the pressure measurement mechanism; instead they use mechanical linkages, springs, a diaphragm, and bellows to detect any applied pressure and result in corresponding movement.

In 1856, Lord Kelvin discovered the piezoresistive effect in metals which was an essential factor in developing strain gauges [33]. Electrical pressure transducers were developed in the early 1930s by applying potentiometers or variable capacitors on a Bourdon tube. In the late 1930s, pressure transducers were developed using strain gauges by applying them on pressure sensitive diaphragms after the invention of independent bonded strain gauges by E. E. Simmons of the California Institute of Technology and AC. Ruge of Massachusetts Institute of Technology [34]. In the mid-1950s, the piezoresistive effect in semiconductors, which is comparatively much higher than its parallel in metals, was found by C. S. Smith, and since then, various kinds of micromachined sensors, including micro pressure sensors, have been widely produced [33,35]. Having strain gauges bonded to a pressure sensitive diaphragm causes inescapable hysteresis and instability. Thin-film transducers with good stability and low hysteresis were introduced in the 1960s by Statham. This technology is particularly useful for high pressure sensors' fabrication. As thin-film technology is more suitable for high pressure 
application, William R. Poyle applied for a patent for a capacitive transducer on glass or quartz basis in 1973, whereas Bob Bell of Kavlico did the same on ceramic basis in 1979 [36].

The automotive industry has been using silicon micromachining since the mid-1970s where primarily pressure sensors were applied to monitor and control air-fuel ratio to improve fuel economy. Since the 1990s micro pressure sensors were applied to detect fuel vapour leak to reduce raw fuel emissions [37].

Having MEMS pressure sensors mass produced with a relatively low unit cost, small weight, micro size and higher precession than conventional pressure sensors, opened a huge market in the automotive industry and made them practical for various pressure related automotive applications. In addition, technological advances in the fabrication of integrated circuits (IC) including doping, etching, and thin film deposition methods, have allowed significant improvements in piezoresistive device sensitivity, resolution, bandwidth, and miniaturization [38]. The relation between ICs and MEMS pressure sensors' micro fabrication evolution over virtually the second half of the 20th century is demonstrated in Figure 3. The next section compares different types of pressure sensing mechanisms within MEMS scale, among which some might be suited for tyre pressure monitoring systems.

Figure 3. Technological advances in IC fabrication (above the horizontal line) and micromachining (below the horizontal line) [38].

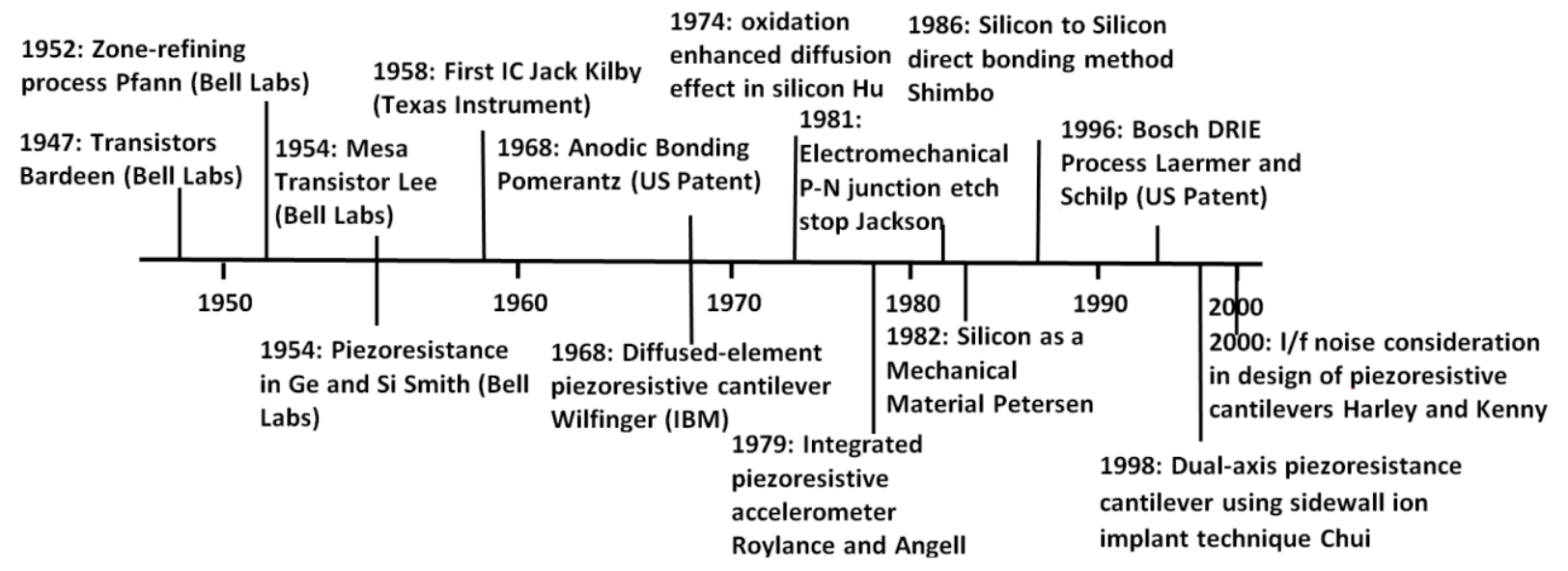

\section{MEMS Tyre Pressure Sensor}

Macroscopic pressure sensors used for detecting pressure greater than atmospheric pressure share a common characteristic with deformable diaphragms, and they are also the case with their micro scale counterparts [35]. Diaphragms are the simplest mechanical structure for pressure sensing and have been employed in micro machined pressure sensors because of their compatibility with a range of bulk and surface silicon micromachining processes [39]. The deflection of the pressure sensitive diaphragm can be detected by either measuring the diaphragm deflection or by measuring the stresses produced in the diaphragm [39,40]. Diaphragms can take different geometries depending on their purpose and whether there is a stress or deformation limitation in that application [41,42]. Figure 4 shows the evolution of diaphragm-based MEMS pressure sensors. 
Figure 4. The evolution of diaphragm-based MEMS pressure sensor [38].

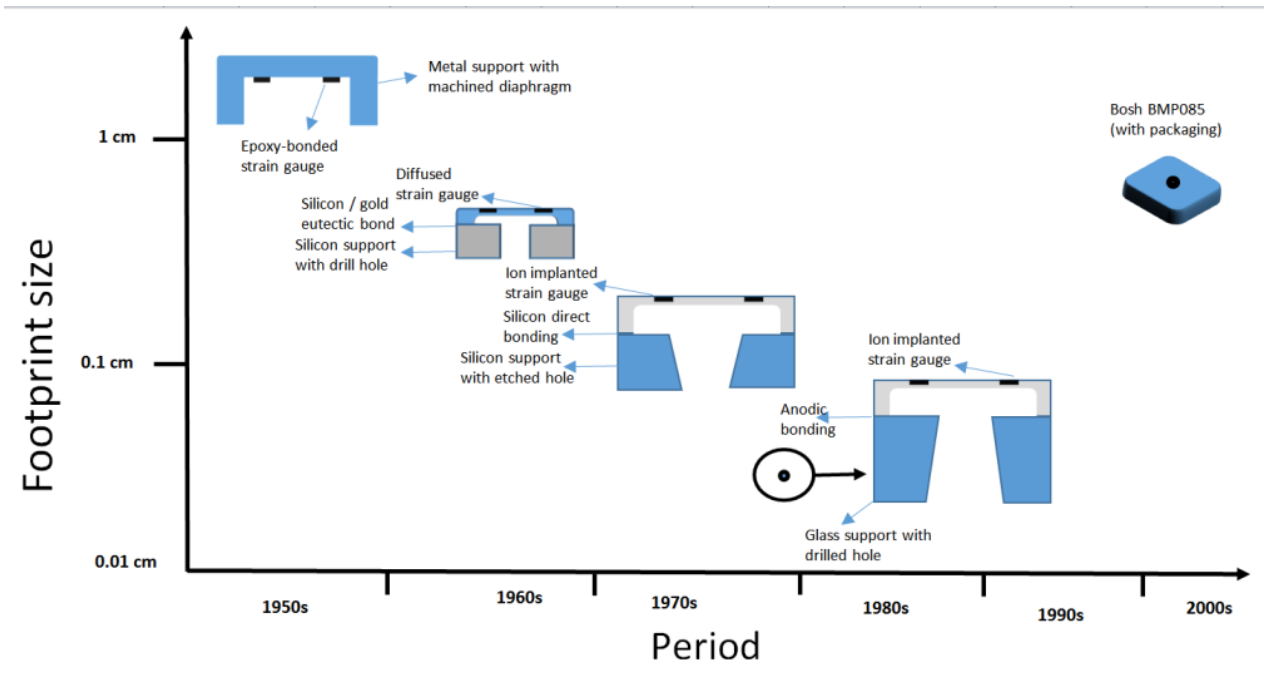

Bossed diaphragms, as shown in Figure 5, are attractive in the case of a traditional bonded strain gauge pressure sensor as they offer mechanical stress amplification.

When pressure is applied on a bossed diaphragm, the developed stresses on the inner and the outer perimeters are the greatest and it is higher than the maximum which occurs in a flat diaphragm [39]. This type of diaphragm offers more sensitivity and linearity in pressure-capacitance response. However, they are more suited for low pressure detection sensors [35,39,43]. In addition, and particularly in TPMS application, having a bossed diaphragm causes considerable error in pressure measurement due to the high centrifugal force up to $3000 \mathrm{~g}$ [23], or shocks from the road up to $1000 \mathrm{~g}$ [27].

In general, diaphragm-based micro machined pressure sensors can be classified, according to the pressure sensing principle, into piezoresistive, capacitive and resonant pressure sensors. These three most common types of MEMS pressure sensors in automotive application, particularly with tyre inflation pressure, are presented and compared in the following sections. Other types of pressure sensors like piezoelectric and optical pressure sensors are outside of the scope of this research due to the high cost and complexity of the measuring chain associated with handling these types of sensors [44], and also because of their high power consumption, which make them not well suited for TCMS application.

Figure 5. (a) Bossed diaphragm geometry and (b) its associated displacement under uniform pressure [39].

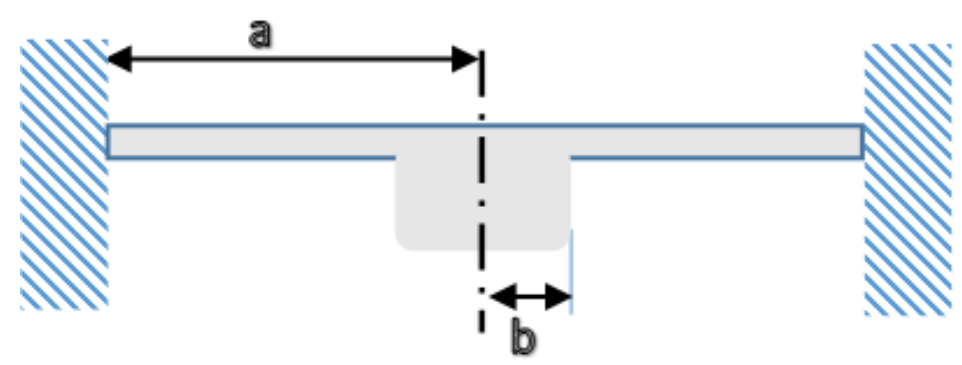


Figure 5. Cont.

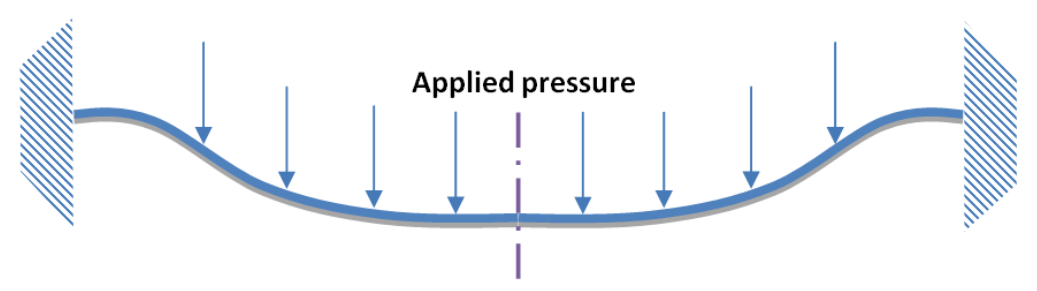

(b)

\subsection{Justification of Focusing A Study on Capacitive Type Pressure Sensors}

A comparison between pressure sensors; piezoresistive, capacitive and resonant pressure sensors, the most used microsensors, is illustrated in Table 1.

Table 1. Performance Features of Resonant, Piezoresistive, and Capacitive Sensing $[39,45]$.

\begin{tabular}{cccc}
\hline Feature & Resonant & Piezoresistive & Capacitive \\
\hline Output form & Frequency & Voltage & Voltage \\
Resolution & 1 part in $10^{8}$ & 1 part in $10^{5}$ & 1 part in $10^{4}-10^{5}$ \\
Accuracy & $100-1000 \mathrm{ppm}$ & $500-10,000 \mathrm{ppm}$ & $100-10,000 \mathrm{ppm}$ \\
Power consumption & $0.1-10 \mathrm{~mW}$ & $\approx 10 \mathrm{~mW}$ & $<0.1 \mathrm{~mW}$ \\
Temperature cross- & $-30 \times 10^{-6} /{ }^{\circ} \mathrm{C}$ & $-1,600 \times 10^{-6} /{ }^{\circ} \mathrm{C}$ & $4 \times 10^{-6} /{ }^{\circ} \mathrm{C}$ \\
sensitivity & High & Low & Low \\
Complexity & & &
\end{tabular}

From Table 1 and the presented literature, it can be seen that capacitive pressure sensors are the least power hungry, which is essential for building a self-powered TCMS. In addition, they have a reasonable temperature sensitivity which is acceptable for the TCMS application.

\subsection{Effects of Diaphragm Geometry on Pressure Sensors' Performance}

Diaphragm based pressure sensors can have various diaphragm shapes, e.g., circular, square or rectangular. Diaphragm geometries react differently when uniform pressure is applied on one side of the diaphragm. Wang and Ko [46] presented a comparison between the three diaphragms shapes' responses under uniformly applied pressure. The diaphragms were compared in two ways; equal areas or equal width. Stress and deflection were simulated using FEA and presented against different applied pressure for all the above mentioned diaphragm shapes. These results show that a circular diaphragm has more advantages over the other diaphragm geometries when diaphragm areas are equal. The lowest maximum stress and the highest sensitivity occur when a circular diaphragm is employed. However, an elliptical diaphragm, with the same area as a circular one, may offer less principal stresses [47,48], in the cost of a slight reduction in sensitivity, in which case extra pressure range and thermal stresses may be covered. Therefore, a comparison between a circular and elliptical diaphragm shape is necessary in terms of obtaining a pressure sensor with acceptable pressure sensitivity, less principal stresses, and low temperature sensitivity. 


\section{Possible Energy Sources for a Tyre Monitoring System}

One of the greatest challenges in having an intelligent tyre system is providing the required energy to power the sensors and circuitry included in it. To power such a system, using a battery could be the easiest option and it is the most common way of powering TPMSs. However, the fact that it has a finite life creates maintenance and disposal problems and environmental impact issues, particularly because of the establishment of TPMS legislation in the US and forthcoming in the EU. Furthermore, tyre cavity boundary conditions, such as centrifugal and impact forces, vibration, and extreme temperatures, are negative factors on battery life and performance. For these reasons, extensive research has been carried out in order to find alternative power sources that are feasible for this system [7,21]. Section 0 explains in more detail the state of the art of energy harvesting in tyres.

Primarily, for a battery-less TPMS, there are two types of powering techniques; passive or remotely powered systems, which could be RF powered, an induction loop system or SAW based sensor node, and active or self-powered systems, which scavenge energy from tyre motion and/or deformation. The latter can be achieved by having a micro power generator that can convert either kinetic -vibration- or strain energy -deformation- into electrical energy using different means of transducers' elements, so called harvesters, e.g., piezoelectric, electromagnetic and electrostatic among which piezoelectric harvesters are the highest power density for micro generators as observed in the literature [49-52]. These energy harvesting techniques will be covered briefly and compared in section 0 with focus on the piezoelectric method, as the latter lies within the research thrust area.

The mechanism, upon which an energy harvester relies, varies in nature depending on the ambient energy source. Chris Knight et al. [53] presents the state-of-the art technology in both energy harvesting and storage for sensor nodes.

As energy harvesting in vehicle tyres is the application in this research, it will focus on evaluating the main harvestable energy within the vehicle tyres' domain during motion conditions. Other energies, e.g., thermal gradient and air flow energies [54-56], are out of the scope of this research due to the large occupancy requirement associated with these types of energy harvesters and their low power density, which make them not well suited, and less reliable than strain energy harvesting, in a TCMS application.

Tyre cyclic deformation, as a result of rolling on a hard surface, offers three main types of a mechanical energy harvesting mechanism; bending, stretching, and vibration. Bending and stretching occur in the tyre contact patch every tyre revolution. Inner liner tyre strain depends on several factors, e.g., load, position and tyre material properties. Inner tyre liner deformation occurs in cyclic bases, preliminary in the contact patch area, as a result of rolling on hard surfaces. This cyclic deformation offers an attractive source for energy harvesting using piezoelectric materials that transform this strain energy into useful electric energy. Choosing an appropriate piezoelectric material can be tricky, mainly because of the amount of tyre strain and temperature dependent conditions [57,58].

Attempts to harvest energy from direct strain energy in a tyre inner surface were carried out by Apollo [58], [59] and Ende et al [57]. In 2005, Apollo achieved a maximum power of $0.9 \mathrm{~mW}$ at $80 \mathrm{~km} / \mathrm{h}$ using a $80 \mathrm{~mm} \times 80 \mathrm{~mm}$ layer of PVDF film piezo element under a $400 \mathrm{~kg}$ load. The main issues are the durability of the piezoelectric harvester, the maximum allowable strain that the harvester can handle and at which temperature range the piezoelectric can function. It was concluded by the 
Apollo project team that PVDF is not suitable for direct strain energy harvesting in tyres due to its lack of resistance to tyre temperature and strain effects, and that Micro Fibre Composite (MFC) is a better candidate for the job. In December 2011, Ende et al [57] were able to develop a new type of PVDF that can remain relatively stable under high temperature conditions compared to an MFC element (Smart Materials), which showed a significant amount of hysteresis between loading and unloading. The issue with the developed PVDF is its low power generation level, which was estimated to generate a maximum of $30 \mu \mathrm{W} / \mathrm{cm}^{2}$ at $50 \mathrm{~km} / \mathrm{h}$ by using a $\left(40 \times 16.5 \mathrm{~mm}^{2}\right.$ of active area) layer of PVDF element (Polyvinylidene fluoride). Due to the viscoelstic nature of the PVDF -piezoelectricity charge coefficient $\left(d_{33}\right)$ value depends on strain rate- and its composite matrices, the power generated at higher speeds is not easy to predict. The results obtained by Ende were based on tyre contact patch length as the main parameter within the range (40-140) $\mathrm{mm}$, loading or inflation pressure have no influence in these analyses.

Cyclic bending within a rolling tyre is another attractive energy harvesting mechanism. In November 2011, Makki [59] presented three energy harvesting techniques within a tyre structure based on tyre deformation in various parts in the tyre, but instead of directly bonding the piezoelectric element to the inner tyre surface, a very thin piezoelectric element was bonded to a reinforcement plate, layer, or ribbon. The first design consisted of a PZT bender bonded to the inner liner of the tyre opposite to the treads; that is a flexible PZT unimorph made of a $25 \mathrm{~mm}$ in diameter PZT on a $44 \mathrm{~mm}$ diameter plate. The second design was a PVDF bender bonded to the tyre. The latter was composed of a $40 \times 40 \mathrm{~mm}^{2} \times 100 \mu \mathrm{m}$ thick PVDF element bonded to a $0.3 \mathrm{~mm}$ thick plastic reinforcement sheet. Both of the first and second designs were bonded on the inner surface of the tyre belt using a very flexible high temperature adhesive to allow the harvester to deform with the tyre while having the least effect on the tyre deformation pattern. The third design contained a PVDF ribbon attached to the tyre bead from side to side; that is a $270 \times 20 \mathrm{~mm}^{2}$ ribbon with 4 PVDF elements attached to it structurally, and connected in parallel with individual rectification circuits electrically. This design is unlike the first and second designs as it is not directly adhered to the tyre, instead it is based on the deformation occurring in the plastic ribbon due to the changing in tyre section height. Experimental tests showed that the first design had the highest energy harvesting rate among the three designs described. At 80 $\mathrm{rpm}$, the first design generated an average power of $4.6 \mathrm{~mW}$ with a peak voltage of $45.5 \mathrm{~V}$. Similarly and under the same motion conditions, the second design generated $0.85 \mathrm{~mW}$ with a peak voltage of $62.3 \mathrm{~V}$, and the third design generated $0.23 \mathrm{~mW}$ and $18.7 \mathrm{~V}$. Different resistive loads were used for each design to approach the maximum power output condition. It's worth mentioning that in the latter study by Makki[59], the tyre deformation criteria was the contact patch length, which was tested within the range $(11.43-16.51) \mathrm{cm}$, based on an average contact patch length of $14 \mathrm{~cm}$ for an average passenger vehicle. The experimental results however showed that the output power has insignificant dependency on the contact patch length, as long as it at least covers the piezoelectric harvester entirely.

As the electric charge generated from the piezoelectric harvester is directly proportional with tyre strain, the value of the generated electric charge can be translated to different quantities. Use of Piezoelectric transducers can be applied to monitor different aspects of tyre conditions, e.g., strain, loading, speed, contact patch dimensions, and friction force. Jingang Yi [60] applied a PVDF transducer on an inner tyre liner to estimate tyre strain by measuring the amount of electric charge generated by the PVDF. In this study, a detailed derivation of the electric charge generated from tyre 
deformation, for both bending and stretching cases, was presented. However, the derived formulae need special equipment to determine individual tyre properties, e.g., friction coefficient, contact patch length, tyre longitudinal stiffness, and the shear modulus of the tyre carcass [60,61]. Numerical attempts were carried out to estimate tyre deformation under different loading and rolling speed conditions by several researchers [62-66]. However, numerical results are not very accurate and experimental investigation is necessary to determine tyre stress and strain and therefore to estimate the performance of a direct strain energy harvester applied to the inner tyre surface.

Tyre vibration is an attractive energy source in which energy harvesting might be applied. Several studies have been completed to measure tyre vibration under different loading and road surface conditions using different techniques. For instance, the Pirelli Tire System project in co-operation with the Mechanical Engineering Department of the Politecnico di Milano have published a paper regarding measurements of pneumatic tyre acceleration under rolling conditions using a three-axial MEMS accelerometer [67]. From this paper, it can be seen that harvestable vibration energy is around the $100 \mathrm{~Hz}$ range. Kindt et al [68] carried out experiments on tyre vibration, and collected experimental data using a Laser Doppler vibrometer and the high power vibration energy density was also around $100 \mathrm{~Hz}$. A similar frequency spectrum pattern was obtained by Roundy [20,49] and Löhndorf et al [21]. Vibration based piezoelectric, electrostatic and electromagnetic micro generators for tyre pressure monitoring have been developed by several researchers and companies [69-79], but in most cases, micro generator performance highly depends on the applied frequency in such a way that it has a quite narrow band width of the efficient power generation level around its resonance frequency which makes it not suitable for the variable excitation frequency environment, such as in land vehicle tyres. However, vibration energy harvesters can be a good option when applied on constant speed machinery by toning their resonance frequencies with the machines' operation speeds. Khameneifar and Arzanpour [80] made a theoretical model for a bending-based energy harvester attached on a pneumatic inner tyre surface in which the generated electric charge was proportional to tyre speed and radial deflection. Calculation findings can be summarised to a prediction of a power generation of approximately $2.95 \mathrm{~mW}$ at $50 \mathrm{~km} / \mathrm{h}$ when a $30 \mathrm{k} \Omega$ load resistor is used. Its also worth mentioning that tyre induced vibration is highly affected by road surface roughness which can change vibration velocity and acceleration amplitudes [67,81]. This can directly affect the amount of the harvested energy when a vibration energy harvester is employed.

Thermal energy is another type of energy dissipated within a pneumatic tyre structure as a result of tyre rolling, which leads to cyclic deformation in the tyre contact patch region. There are quite a few available published experimental data for tyre temperature build up under different loading and speed conditions. The following paragraph presents some published experimental and simulated pneumatic tyre temperature data under different loading and rolling speed conditions and using different techniques.

Clark and Dodge [82] presented steady state tyre pressure and temperature data; as initial tyre cavity pressure and temperature values were measured. Experiments under various loading and speed conditions were then carried out. After a period of time in which the measured values approached equilibrium, tyre air cavity pressure and temperature values were measured again. Gusakov [83] reported tyre air pressure and temperature data measured over time which were collected using a micro computer attached to the rim, from which data was downloaded subsequently. Wilburn [84] collected 
steady state tyre structure temperatures, e.g., sidewall and tread, using a thermal imaging technique. This technique does not actually apply to measuring air temperature inside the tyre cavity.

Due to the difficulties and challenges associated with real-time tyre condition monitoring, FEA simulation has been used by several researchers to estimate tyre structure temperature [85-88]. However, tyres are made of several composite materials which change noticeably with tyre boundary conditions. As such, simulation results remain very approximate.

The tyre rolling mechanism dictates cyclic deformation of tyres. Due to rubber mechanical properties and hysteresis loss, heat is generated in the tyres. The amount of heat generated is related to factors such as: the applied radial load and speed. On the other hand, tyre equilibrium temperature depends on, in addition to radial load and speed, other environmental conditions, such as road temperature, air flow speed, ambient temperature, the temperature of the parts surrounding the tyre, solar radiation and the distance travelled from the cold start. Tyre tread thickness, ply number and orientation, and the amount of torque applied to the wheel are also important factors in tyre cavity equilibrium temperature. Having such various environmental conditions and different tyre geometries, properties and loading conditions, it is very difficult to estimate air temperature inside the tyre cavity by using numerical methods. This raises the need for acquiring real time tyre cavity air temperature. Tyre cavity temperature could be increased by $35{ }^{\circ} \mathrm{C}$ with respect to ambient temperature in average urban driving conditions [82] and tyre tread temperature is higher than the sidewall temperature by an average of $6{ }^{\circ} \mathrm{C}$ [84]. Numerical analysis shows tyre tread temperature can rise to as high as $100{ }^{\circ} \mathrm{C}$ or more [85].

From the above, it can be seen that there is a potential source of thermal energy within the tyre structure for energy harvesting purposes, although tyre response to change in temperature is not quick enough for the TCMS application. However, the nature of a thermal energy harvesting system requires large size devices and a reasonable temperature difference which is not the case inside a rolling tyre environment. A possible example of a commercially available thermoelectric energy harvester that is utilizable for powering TPMS is the thermoelectric module (CP10,31,05) of Laird Technologies plc (London, UK) [6].

Another type of energy available inside a rolling tyre is air flow. D. Wang et al [55] suggested employing an air flow based piezoelectric energy harvester into the tyre cavity to power tyre pressure monitoring systems. The authors claim harvesting a maximum power of $1.1 \mathrm{~mW}$ with an average air flow speed of $1.083 \mathrm{~m} / \mathrm{s}$. The device however has large dimensions $-758.5 \mathrm{~mm}$ - which make the system not very practical for a tyre monitoring system application.

In this research, direct strain energy harvesting in particular is going to be investigated and closely examined for its high power density, reasonable cost, and lowest overall mass, making it the best candidate among above described energy harvesting means for powering TPMS.

\section{Main Methods of Energy Harvesting}

The following sections review and discuss some main methods of energy harvesting in order to decide which technique is the most suited for the tyre monitoring system. 


\subsection{Electromagnetic Energy Harvesting}

Electromagnetic, or as it is sometimes called electrodynamic, energy harvesting is based on Faraday's law of electromagnetic induction; as such, a combination of a coil and a magnet with a relative velocity between them comprises electromagnetic harvesters. To achieve this mechanism, linear vibration is primarily the most common configuration of electromagnetic energy harvesters. A typical example of a traditional electromagnetic energy harvester is shown in Figure 6 below. However, a large proportion of the harvesters in the literature have the configuration of a cantilever beam with a seismic mass attached to the free end of the beam, which can be either the magnet or the coil of the harvester [50,89]. The theory behind electromagnetic energy harvesting is explained by Saha et al [90]. The advantages of this type of energy harvester are its design simplicity and that it is possible to make it in such a way that its resonance frequency matches the excitation frequency for which the harvester is designed, purely by selecting the appropriate spring element. This however means that the designed system is limited to a particular frequency and only practical for constant vibration frequency applications. In addition as the harvester power generation depends on the relative velocity and change in magnetic flux, of which its amplitude is not limited by its fatigue strength, for example, piezoelectric material [91].

Figure 6. Schematic of a traditional electromagnetic energy harvester [92].

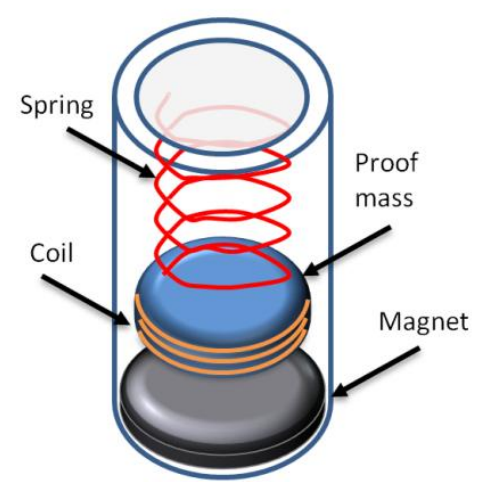

One of the main disadvantages of electromagnetic energy harvesters is their low output voltage and low power density $[49,50,93,94]$, which make it difficult to harvest energy effectively, particularly for the research target application. Another fact was observed in the literature; scaling down an electromagnetic harvester to MEMS scale usually influences the system to have a resonance frequency higher than the research application frequency band width, 0 to $100 \mathrm{~Hz}[89,95]$. Some of the main suppliers of commercial vibration based electromagnetic energy harvesters are Ferro Solutions Inc. (USA), MicroStrain Inc. (USA), EnOcean GmbH (Germany), and Perpetuum Ltd. (UK). A presented list for such harvesters can be found in $[50,52,96]$.

\subsection{Electrostatic Energy Harvesting}

The electrostatic principle is the simplest among the energy harvesting techniques. It relies on the relative motion between the two plates of a charged capacitor, acting as a variable capacitor $\left(C_{\mathrm{v}}\right)$, while containing the same electric charge $(Q)$. Consequently, a change in the electric potential $(V)$ across the 
capacitor will occur $(Q=C V)$. Figure 7 below shows different types of electrostatic energy harvester configurations.

Figure 7. Types of electrostatic energy harvesters [93].

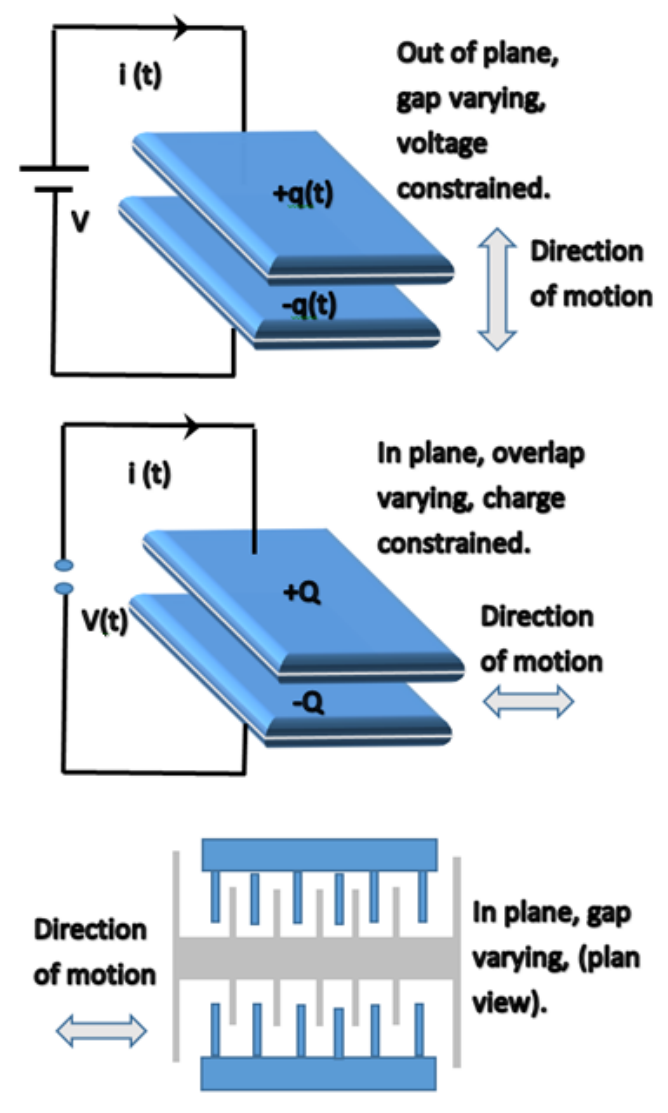

The main advantage of this type of energy harvester is their compatibility of being micromachined, integrated and produced along with application microchips, such as sensors, to act as their power source and supply them with electrical power whenever energy harvesting occurs. When energy harvesting is in the micro scale, micromachined electrostatic harvesting systems have a better coupling coefficient when compared to electromagnetic systems. In terms of the level of the direct generated voltage in electrostatic harvesters, it is usually within an appropriate level for most electronic circuitries [49]. However, there is a risk of contact between the electrodes of the capacitor [94]. Also, the fact that electrostatic harvesters have to be charged initially, or at least once in a while, due to electric charge leakage, makes them incapable of being the main power source; therefore they are more suited for recharging batteries and acting as an auxiliary power supply, which is not preferred for the research application. Design and analysis of an electrostatic energy harvester is explained in [49,93]. A recent summary of the state of the art electrostatic energy harvesters can be found in $[50,96]$.

\subsection{Piezoelectric Energy Harvesting}

After the discovery of the piezoelectric phenomena within certain types of materials in the late 19th century [97], the piezoelectric effect has been applied in different sensing and transduction applications. The main benefit of this effect is the direct conversion of mechanical stress, strain, or 
deformation, occurring in a piezoelectric material, into electrical charge and vice versa. The former is termed as the direct piezoelectric effect, which is of interest in this research, and the latter termed as the piezoelectric converse effect (Figure 8). The amount of the produced electrical charge depends on the piezoelectric material properties and in proportion with the mechanical stress or deformation applied onto it. Different mechanisms of energy harvesters based on the piezoelectric effect have been produced. A cantilever-based resonant structure is the most common among piezoelectric energy harvesters in the literature, in which mechanical vibration energy is converted to electric charge. This is probably because of the simplicity of fabricating such a design, whether in macro or micro size.

Figure 8. Macroscopic piezoelectric effect, direct (left), converse (right) [98].
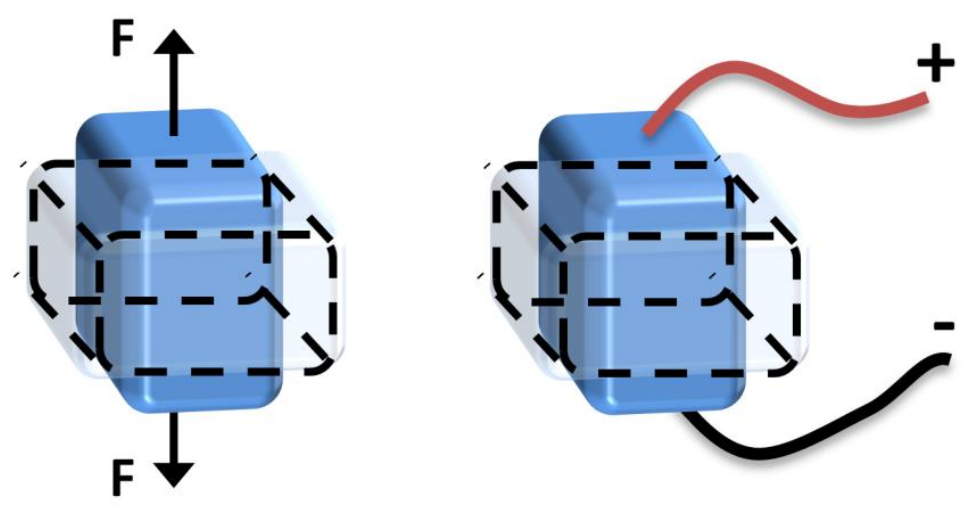

As mentioned earlier, the only issue with resonance based energy harvesters is their low performance whenever the excitation frequency is not close to the resonance frequency. However some multi-resonance structures have been promoted [99-101]. This however leads to a large harvester volume and problems associated with the harvester structure reliability [93]. Some examples of main suppliers of commercial piezoelectric vibration based energy harvesters are MicroStrain Inc. (Willston, VT, USA), EoPLEX Technologies Inc. (San Joes, CA, USA), and Mide Technology Corporation (Meddord, MA, USA). Some leading manufacturers of piezoelectric transducers for the purpose of energy harvesting are PI (Physik Instrumente) Ltd., (Karlsruhe, Germany), Smart Materials Corp., (Dresden, Germany), and Advanced Cerametrics Inc., (Lambertville, NJ, USA). The latter has been producing a product made with piezoelectric fibres, so called Piezo Fibre Composite (PFC) (Advanced Cerametrics, online [Available: http://www.advancedcerametrics.com/] [Accessed on 1 October 2010]) [102] with high mechanical to electrical energy conversion and it also has a quite light ( $2 \mathrm{~g})$ and flexible format compared to other commercial bulk PZT elements [103].

Having the generated electric charge in a piezoelectric element proportional to the amount of subjected stress, some designs are based on harvesting the strain energy directly without the complications of a vibration mechanism [104,105]. This makes the device functional over a wider frequency range and generates energy almost linearly with the applied frequency. Coupling piezoelectric with the electromagnetic techniques is also another way to enhance the amount of harvested energy [106-108], but again it means more mass and not particularly higher power density. Different types of techniques used in piezoelectric energy harvesters are presented in [50,52,93,109].

Piezoelectric harvesters can operate in two main different modes; 31 and 33 as shown in Figure 9. The vast majority of the piezoelectric energy harvester designs operate in the lateral 31 mode, 
particularly when the piezoelectric element is adhered onto a geometry that converts vertical displacement into a lateral strain. Some designs, however, operate on the 33 mode, which is a function of the compressive strain, because it usually has constants higher than the 31 modes. Mode 33 can be exploited, even under lateral strain loading conditions, when the piezoelectric element is structured within inter digital transducer geometry as shown in Figure 10 [93].

Figure 9. Piezoelectric constants in typical energy-harvesting modes [93].

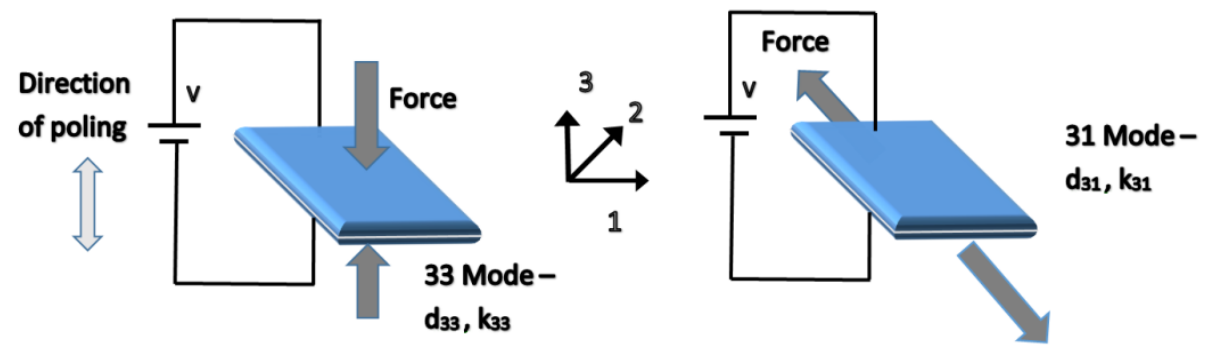

Figure 10. Interdigital electrode arrangement [107].

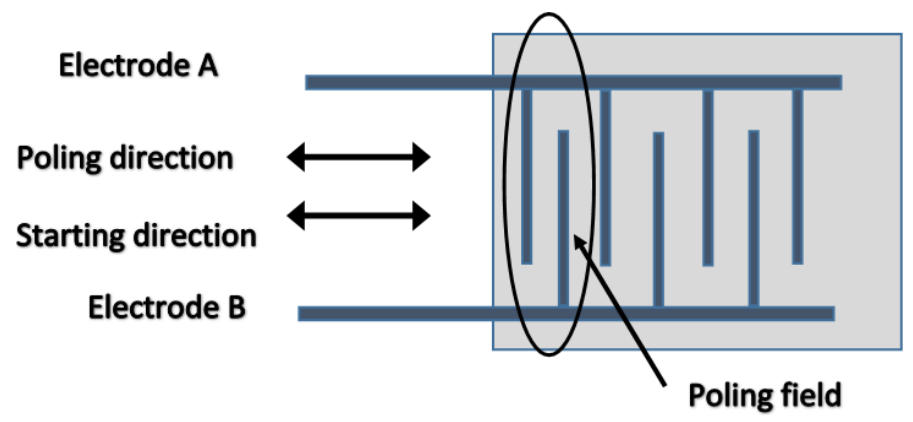

One of the limitations when a piezoelectric element is applied onto a flexible surface to harvest direct strain energy is the amount of strain transferred to it. This strain must not exceed a certain limit to avoid any fatigue damage in the piezoelectric element. In most commercial piezoelectric elements, the substrate -on which the piezoelectric material is printed- is brittle and has relatively low strain limits. In Princeton University, a group of researchers developed a method to print piezoelectric ceramics onto a rubber substrate to obtain a stretchable energy harvester, e.g., in implantable or wearable energy harvesting systems [110]. Further investigation is yet needed to integrate this type of energy harvester with an electronic circuit and power management units.

\subsection{Thermal Energy Harvesting}

Certain combinations of materials, metal alloys or some semiconductors can generate electricity when subjected to a temperature gradient [111]. This phenomenon, which is known as the Seebeck effect, has been applied in various devices in order to achieve different purposes; e.g., thermocouples for temperature measurement, and thermal energy harvesters. A schematic diagram for the Seebeck effect and a general thermal energy harvester is shown in Figure 11. 
Figure 11. The Seebeck effect: a voltage generated by the temperature difference across the junctions [111].

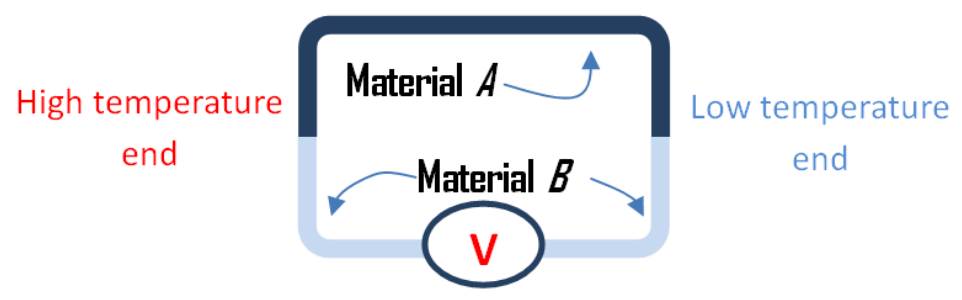

Although it is still not mature enough and more research is necessary to promote this technique, commercial thermoelectric products for thermal energy harvesting purposes are available in the market [53]. However, these harvesters are usually quite expensive. In addition, in order to generate a sustainable electric power, a considerable temperature difference is required and the average size and weight of such harvesters exceed that of the harvesters which use the techniques described earlier.

Commercially available thermoelectric devices are bulky and rigid [111], and they are not suitable to install in moving parts such as pneumatic tyres, which is the target application of this research. Some of the main suppliers of such devices are Marlow Industries Inc. (Dalas, TX, USA), Micropelt (Germany), Enocean GmbH (Munich, Germany), Nextreme Thermal Solutions (Durham, NC, USA), Tellurex Corp. (Traverse city, MI, USA), and Laird Technologies / Thermal Solutions (London, UK). The latter has developed a practical and compact design for thermal energy harvesting purposes, but its cost is still relatively high for the research target application.

Knight and Davidson [56] presented a thermal energy harvester which can generate a reasonable electrical power, sufficient for most wireless sensor nodes' applications; $50 \mathrm{~mW}$ when the temperature difference is $20^{\circ} \mathrm{C}$. The generated power in the latter is proportional to the temperature difference, and the device uses a relatively large space to operate efficiently [50]. Successful attempts to harvest thermal energy using micro scale thermoelectric elements for powering a wrist watch, are reported in [111], the high cost, however, makes such systems uncompetitive for commercialization. More details about thermal energy harvesters' theory and principles can be found in [111].

\subsection{Justification of Focusing on Piezoelectric Energy Harvesting}

S. Roundy is a well know researcher in the field of energy harvesting. He developed an admirable piece of work in the field of vibration based energy harvesting, including the three main methods of energy harvesting; electrostatic, piezoelectric and electromagnetic, with a detailed comparison to determine which method is the most efficient in terms of energy density [49]. He concluded that using piezoelectric offers the highest power density. Emma L. Worthington [50] carried out a comprehensive study on energy harvesting means, and made a detailed comparison of them, from which she made a similar conclusion. Similar comparisons and conclusions can be found in [51,52,93,96,112]. M. Pereyma [113] and P. Mitcheson et al [114] argue that at low frequency levels piezoelectric energy harvesters are more powerful than electromagnetic, however, at high frequency applications electromagnetic harvesters are more reliable. Having low frequencies with the highest extractible energy levels experienced by tyres under rolling conditions, low frequency levels piezoelectric energy extraction is more suited for the TPMS application. 
One of the main advantages of the piezoelectric energy harvesting technique over the electrostatic technique is the lack of necessity for any external power source or any initial charge applied to it, which makes it a an excellent choice for the research application. The performance of each piezoelectric material depends on its material properties. The constitutive equations that relate the mechanical and electrical properties of the piezoelectric transducers are presented in [115].

\section{Power Management Circuitry and Energy Storage Techniques}

The generated electric charge in virtually all the energy harvesting techniques, and at least for those previously discussed, require power management circuitries, through which the harvested energy from the harvester is adapted to suit a particular application load. Firstly, rectification is required if the generated energy is in an alternating current, such as in electromagnetic, electrostatic and piezoelectric energy harvesting techniques. This is usually done by using a diode bridge rectifier. Then, an energy storage element is required to act as a reservoir, which can be either a rechargeable battery or a capacitor. The next stage is conditioning the output power to an appropriate voltage to supply sufficient current, depending on the nature of the system load. This can be carried out in several different ways; e.g., by using a DC-DC converter [49], or by using op-amps and comparators [116]. A voltage multiplier can be used to step-up the generated voltage especially when the voltage level of the generated charge is not high enough [117].

Various power management schemes have been introduced in order to slightly increase the efficiency of particular energy harvesters, e.g., electric tuning in which the load impedance is adjusted [93,118], impedance matching techniques [119], and a switching technique [50,120]. However, adding extra electrical components increases the cost and complexity of the system. Regarding the energy storage options, different comparisons between capacitor and rechargeable batteries are presented in the literature. Roundy [49] shows that capacitors have the advantage of the flexibility of their charging up method, and their infinite lifetime, over rechargeable batteries. In addition, rechargeable batteries' leakage escalates with the batteries' aging and becomes dominant in terms of power loss, although batteries have higher energy density than capacitors.

Guan and Liao [121] conducted experiments to investigate the efficiency of the energy element for both rechargeable batteries and super capacitors in piezoelectric based energy harvesting systems. In the former, it was found that leakage resistance is the main drawback within the energy storage element, and that super capacitors have many advantages over rechargeable batteries, e.g., leakage resistance, adaptability, lifetime, and the lack of necessity for charging protection circuitry.

H. Sodano et al [122] carried out experimental tests to examine different piezoelectric materials' performance in terms of their efficiencies in charging different rechargeable batteries. This showed that a piezoelectric element must be chosen carefully when it is used to recharge a particular rechargeable battery when applied in an energy harvesting system; which is not the case when a capacitor is used as the energy storage element [49].

Squires [123], from Infinite Power Solutions Inc. (Littleton, CO, USA), presented a comprehensive comparison between different energy harvesting storage devices in the first annual workshop on Micro Power Technologies in 2009 . The presentation shows that high temperature $\left(50-85^{\circ} \mathrm{C}\right)$ is a drawback in general for all types of energy storage, and particularly for super capacitors, as it leads to reduction 
in their lifetime. Also, super capacitors have a high charge threshold acceptance; that is bulky energy harvesters are necessary. However, they can handle high discharge rates (>100 mA) and a high number of charge cycles $\left(>10^{6}\right)$. Rechargeable AA/AAA batteries have a high energy capacity and are suited for high power applications; however, they have high leakage rates (>40\%/year), and low cycle life, 1000 at $80 \%$ depth of discharge (DOD), i.e., not suited for micro power applications. Due to higher internal resistance in rechargeable coin batteries, low discharge rates $(<200 \mu \mathrm{A})$ are a problem. Compared to AA/AAA batteries, coin batteries have lower cycle life (500-1000 at 80\% DOD), although they are smaller in size and have less discharge rates (2\%-5\%/year), making them suitable to act as a backup power source. Thin-film batteries, the product of Infinite Power Solutions Inc. (USA), have the advantage of being very thin in geometry $\left(25 \times 25 \times 0.17 \mathrm{~mm}^{3}\right)$, and have a high cycle life (>10,000 at $80 \%$ DOD), low discharge rate (2\%-5\%/year), and very low charge acceptance threshold $(<100 \mathrm{nA})$ making them well suited for micro energy harvesters. Low temperature and shelf life ( $<10$ years), however, are dangerous enemies of energy storage. The thin-film battery product comes with its power management circuit monolithically. Other ready to use commercial power management units are available from the following suppliers; Linear Technology Corp. (Milpitas, CA, USA), MicroStrain Inc. (USA), EnOcean GmbH (Germany), Texas Instruments Inc. (Dalas, TX, USA), and Advanced Linear Devices Inc. (Sunnyvale, CA, USA).

In order to select a power management circuitry that is well suited for TPMS, essential characteristics have to be taken into consideration. For instance, it is desirable to utilize a high efficiency energy storage unit; that is by minimizing electric charge leakage and increasing reliability against tyre thermodynamics and kinetics. Another important property is system durability. Charging-discharging cycles and shelf life are expected to last long enough for to be installed within a passenger vehicle tyre. This is at least approximately a travelling distance of 20 thousand miles. As wheel balance is crucial for safe and convenient driving, system weight and volume preferred to be minimal. Energy requirement for TPMS evokes using an energy source and storage that can supply steady voltage while a relatively high current in a short time; that is pulsatile loading which occurs during signal transmission. It is worth mentioning that signal transmission drains most of harvested energy if high transmission rate is needed. Taking sensors measurements consumes the second biggest portion of harvested energy, but still less than signal transmission power consumption even if high sampling rate is used. All above indispensible characteristics and energy requirements suggest using an electric capacitor for energy storage as it can have very small leakage, adapts to pulsatile loading, and more resistive to rolling tyre thermodynamics than other energy storage schemes, e.g., batteries.

\section{Tyre Monitoring Systems}

In this section, the state-of-the-art of tyre monitoring systems is presented. The idea of mounting a tyre monitoring system first started in order to monitor tyre inflation pressure, the most crucial parameter on which tyre performance relies. The first mounted system was for a Porsche 959 in 1986 [124], and since then, millions of such devices have been installed in other cars [125]. Not only pressure measurement has been applied in tyre monitoring systems, but in addition air temperature, as the second most important parameter to measure in a rolling tyre. Other tyre parameters, e.g., strain, 
acceleration, wear, etc. are being investigated and monitoring systems to include measuring these parameters are under development $[62,126]$ in order to promote an intelligent tyre system.

In general, tyre monitoring systems focus on the measurement of tyre inflation pressure, especially after establishing the TPMS legislation (Standard No. 138 (Lemon Law Center, online, [Available: http://lemon.onecle.com/fmvss-standard-no-138/] [Accessed on: 4 May 2012])) [15,127]. The main reasons why such legislation was created were the reported deaths (over 100) and injuries (about 700) due to rollover car accidents in the late 1990s [128].

Tyre inflation pressure, in the conventional way, can be monitored using air pressure sensors; that is a direct TPMS, or using unconventional methods when other parameters are measured; that is an indirect TPMS, e.g., by measuring tyres' angular speeds individually and comparing them to each other [129,130]. Indirect TPMSs existed as a cheaper alternative for direct TPMSs, but at the price of accuracy and detection time. Moreover, preliminary statistical and simulation data show that an indirect TPMS can only detect half of existing under-inflations by $25 \%$ or more [131], because in some cases, under-inflation is undetectable in an indirect TPMS; e.g., when two tyres are on the same side, on the same axle, or all four tyres are equally under-inflated. A compromise solution is a hybrid TPMS; that is a combination of both direct and indirect TPMSs, in which fewer tyre pressure sensors are used. In the latter only two diagonally located tyres are equipped with both direct and indirect TPMSs [28].

Direct TPMSs can be either battery powered; that is an active system, which is the case for the vast majority of the TPMS products on the market, or remotely powered; that is a passive system, thereby the system receives its required energy wirelessly, e.g., by means of an electromagnetic field [125]. This system has a major installation drawback due to the need for a complex wiring network to be installed for both powering and reading out purposes. A general comparison between direct and indirect TPMSs is shown in Table 2. A wide range of various TPMS types is presented in [132].

In the literature, various techniques have been applied in TPMS designs for powering and/or transmitting tyre inflation pressure data; e.g., RFID, SAW, BAW, and induction loop. Similarly, different mechanisms of energy harvesting methods to supply a TPMS with the required electrical energy have been investigated, and based on different types of energies; e.g., vibration , direct strain, tyre-rim assembly kinematics, bending within the tyre structure, and air flow inside the tyre. Table 3 , Table 4, and Table 5 show state of the art various published TPMS designs; possibly more are being researched and investigated but are not accessible due to patent reasons.

Active TPMSs are conventionally powered by batteries. Battery-less TPMSs usually refers to remotely powered systems (passive TPMS), but also can be used to describe a TPMS powered by energy harvesting. The former has a hidden disadvantage; that is draining the vehicle battery [133], as remotely powering is actually using the vehicle battery and thereby they are technically battery powered. The latter is the type of TPMS that is legitimately battery-less, so called self-powered TPMS which is the target of this research. The SAW sensor, for example, consumes around $10 \mathrm{~mW}$ [134], which is still low comparing to other car electrical devices, e.g., headlights, which consume around 50 W (MK6 Ford Fiesta). However, active TPMSs power consumes less than passive TPMSs, with a power consumption around 200-250 $\mu \mathrm{Ws}$ for a Stateof-the-Art TPMS module [135]. 
Table 2. Comparison between direct and indirect TPMSs [29,136].

\begin{tabular}{|c|c|c|}
\hline & Direct TPMS & Indirect TPMS \\
\hline Costs & High & Low \\
\hline Physical parameters & Pressure and temperature & Rolling speed \\
\hline Hardware & $\begin{array}{c}\text { Wheel sensor, receiver and } \\
\text { display }\end{array}$ & $\begin{array}{c}\text { ABS sensor, ABS control unit, } \\
\text { display }\end{array}$ \\
\hline Measuring of pressure & Absolute & $\begin{array}{c}\text { Relative (30\% aberration from set } \\
\text { value) }\end{array}$ \\
\hline Measuring of temperature & Yes & No \\
\hline Target values & $\begin{array}{c}\text { Fixed maximum pressure is } \\
\text { to be set }\end{array}$ & $\begin{array}{c}\text { Learning of default values is } \\
\text { required }\end{array}$ \\
\hline Detection time & $\begin{array}{c}\text { Almost real time, } \\
\text { independent of driving } \\
\text { manoeuvre, while moving } \\
\text { or at rest }\end{array}$ & $\begin{array}{c}0.6 \text { bar under-inflation are } \\
\text { detected within } 5 \text { min at } \\
130 \mathrm{~km} / \mathrm{h} \text { (e.g., Dunlop WarnAir) }\end{array}$ \\
\hline $\begin{array}{l}\text { Susceptibility of wheel } \\
\text { components to damage during } \\
\text { tyre installation and removal }\end{array}$ & More likely & Less likely \\
\hline $\begin{array}{l}\text { Need for an independent power } \\
\text { supply }\end{array}$ & Yes & No \\
\hline $\begin{array}{l}\text { Need to reset after a vehicle's } \\
\text { tyres are replaced or rotated }\end{array}$ & Yes & Yes, system must recalibrated too \\
\hline $\begin{array}{l}\text { Ability to detect loss of air if all } \\
\text { tyres lose pressure }\end{array}$ & Yes & No \\
\hline $\begin{array}{l}\text { Ability to detect small pressure } \\
\text { losses }\end{array}$ & Yes & No \\
\hline $\begin{array}{l}\text { Ability to detect under-inflated } \\
\text { tyre while vehicle is stationary }\end{array}$ & Yes & No, vehicle must be moving \\
\hline $\begin{array}{l}\text { Ability to detect which tyre is } \\
\text { underinflated }\end{array}$ & Yes & No \\
\hline $\begin{array}{l}\text { Susceptibility to giving false } \\
\text { indications of a significantly } \\
\text { under-inflated tyre }\end{array}$ & No & $\begin{array}{l}\text { Yes, if the vehicle is being driven } \\
\text { on gravel or bumpy roads at high } \\
\text { speeds }(112 \mathrm{~km} / \mathrm{h} \text { ) or if it has } \\
\text { mismatched tyres of a tyre out } \\
\text { balance or out of alignment }\end{array}$ \\
\hline
\end{tabular}

From Table 3, Table 4, and Table 5 it can be seen that a lot of energy harvesting approaches for powering TPMSs have been investigated, however, only a few were actually applied into a tyre-rim assembly. This is due to the challenges associated with having such a system installed within a tyre-rim assembly, particularly the extreme levels of centrifugal acceleration of up to $3000 \mathrm{~g}$ [23]. 
Table 3. Summary of published research for various types of battery powered TPMS for passenger vehicles.

\begin{tabular}{|c|c|c|c|c|c|}
\hline Power Source & Size & $\begin{array}{c}\text { Pressure Sensor } \\
\text { Type } \\
\end{array}$ & $\begin{array}{c}\text { Other sensors } \\
\text { within the System } \\
\end{array}$ & Location within the Tyre & Source \\
\hline Lithium battery & - & $\begin{array}{l}\text { A magnet and Hall } \\
\text { effect IC }\end{array}$ & - & On wheel disk & $\begin{array}{c}\text { Uemura et al., } \\
1985 \text { [129] }\end{array}$ \\
\hline Lithium battery & $\begin{array}{c}1.2 \times 1.3 \times 0.64 \\
\mathrm{~cm}^{3}\end{array}$ & BAW & temperature & $\begin{array}{l}\text { Not tested, expected to be } \\
\text { applied on tyre inner liner }\end{array}$ & $\begin{array}{c}\text { Flatscher } \\
\text { et al., } 2009 \text { [23] }\end{array}$ \\
\hline Lithium battery & - & Capacitive & temperature & - & $\begin{array}{c}\text { Rudolf et al., } \\
1997 \text { [22] }\end{array}$ \\
\hline Lithium battery & - & Piezoresistive & temperature & Rim mounted & $\begin{array}{c}\text { Jian Zhang } \\
\text { et al., } 2011 \text { [24] }\end{array}$ \\
\hline $\begin{array}{l}\text { Passive (Magnetic } \\
\text { coupling) }\end{array}$ & - & Piezoresistive & $\begin{array}{l}\text { temperature, force } \\
\text { vector }\end{array}$ & Rim and hub & $\begin{array}{c}\text { VisiTyre, } 2003 \\
{[137]}\end{array}$ \\
\hline Passive & - & - & - & - & $\begin{array}{c}\text { Kurashige } \\
\text { et al., } 1982 \\
{[138]}\end{array}$ \\
\hline Passive (SAW) & - & SAW & temperature & Valve stem & $\begin{array}{c}\text { Transense, } 2006 \\
{[139]}\end{array}$ \\
\hline Passive (SAW) & - & $\begin{array}{l}\text { Hybrid (SAW and } \\
\text { capacitive) }\end{array}$ & temperature & Rim mounted & $\begin{array}{c}\text { Siemens, } 2000 \\
{[140]}\end{array}$ \\
\hline Vehicle battery & - & $\begin{array}{c}\text { (Indirect) wheel } \\
\text { velocity }\end{array}$ & - & - & $\begin{array}{c}\text { Qi Zhang } \\
\text { et al., } 2009 \\
\text { [130] }\end{array}$ \\
\hline Passive (RFID) & - & - & temperature & $\begin{array}{l}\text { Annular, attached to inner tyre } \\
\text { liner }\end{array}$ & $\begin{array}{l}\text { Deicke } \text { et al., } \\
2009[141]\end{array}$ \\
\hline $\begin{array}{l}\text { Passive (magnetic } \\
\text { coupling) }\end{array}$ & - & $\begin{array}{c}\text { Capacitive using LC } \\
\text { circuit }\end{array}$ & temperature & Proposed design & $\begin{array}{c}\text { Nabipoor and } \\
\text { Majlis, } 2006 \\
\text { [142] }\end{array}$ \\
\hline Passive (RFID) & - & $\begin{array}{c}\text { Capacitive } \\
\text { (MPXY8000) }\end{array}$ & temperature & Rim mounted (prototype) & $\begin{array}{c}\text { Ho et al., } 2009 \\
\text { [143] }\end{array}$ \\
\hline Passive (RFID) & & & & & \\
\hline $\begin{array}{l}\text { +Electromagnetic } \\
\text { energy harvesting }\end{array}$ & - & BAW & temperature & $\begin{array}{l}\text { Dedicated design, mounted on } \\
\text { inner tyre liner }\end{array}$ & $\begin{array}{l}\text { Gruber } \text { et al., } \\
2010[144]\end{array}$ \\
\hline Power source & Size & Pressure sensor type & $\begin{array}{l}\text { Other sensors } \\
\text { within the system }\end{array}$ & Location within the tyre & Source \\
\hline $\begin{array}{l}\text { Passive (Magnetic } \\
\text { coupling) }\end{array}$ & $\begin{array}{c}\text { Diameter }=2.5 \\
\mathrm{~cm} \times \\
1 \mathrm{~cm}+\text { coupling } \\
\text { ring (antenna) }\end{array}$ & $\begin{array}{l}\text { BAW (cantilever - } \\
\text { based quartz } \\
\text { resonator linked to a } \\
\text { pressure sensitive } \\
\text { diaphragm) }\end{array}$ & - & Fixed at the rim of the wheel & $\begin{array}{l}\text { Grossmann, } \\
1999[145]\end{array}$ \\
\hline
\end{tabular}


Table 3. Cont.

\begin{tabular}{|c|c|c|c|c|c|}
\hline Power Source & Size & $\begin{array}{c}\text { Pressure Sensor } \\
\text { Type }\end{array}$ & $\begin{array}{c}\text { Other sensors } \\
\text { within the System }\end{array}$ & Location within the Tyre & Source \\
\hline Passive (RFID) & - & $\begin{array}{l}\text { BAW (quartz-based } \\
\text { resonator with } \\
\text { acoustic mirror) }\end{array}$ & - & - & $\begin{array}{c}\text { Flatscher } \text { et al, } \\
2008[146]\end{array}$ \\
\hline Passive (SAW) & $\begin{array}{c}7 \times 5.3 \mathrm{~mm}^{2} \\
\text { (approximately) }\end{array}$ & SAW & - & $\begin{array}{l}\text { Built inside the tyre valve } \\
\text { housing }\end{array}$ & $\begin{array}{c}\text { Varadan } \\
\text { et al, 2001 [147] }\end{array}$ \\
\hline
\end{tabular}

Table 4. Summary of published research for self-powered TPMS using various energy harvesting means.

\begin{tabular}{|c|c|c|c|c|c|c|}
\hline $\begin{array}{l}\text { Energy } \\
\text { Harvesting } \\
\text { Mechanism } \\
\end{array}$ & $\begin{array}{l}\text { Harvesting } \\
\text { Technique }\end{array}$ & Size & $\begin{array}{l}\text { Pressure } \\
\text { Sensor } \\
\text { Type } \\
\end{array}$ & $\begin{array}{l}\text { Other Sensors } \\
\text { within the System }\end{array}$ & $\begin{array}{l}\text { Location } \\
\text { within the } \\
\text { Tyre }\end{array}$ & Source \\
\hline $\begin{array}{l}\text { Compression of } \\
\text { a very thin brass } \\
\text { reinforced PZT } \\
\text { at the tyre-bead } \\
\text { rim interface }\end{array}$ & $\begin{array}{l}\text { Piezoelectric (the } \\
\text { amount of the } \\
\text { harvested energy is } \\
\text { directly proportional } \\
\text { with tyre speed) }\end{array}$ & - & $\begin{array}{l}\text { Piezoresistiv } \\
\text { e pressure } \\
\text { sensor } \\
\text { (CPX100G) }\end{array}$ & - & $\begin{array}{l}\text { Mounted at } \\
\text { the tyre-bead } \\
\text { rim interface }\end{array}$ & $\begin{array}{l}\text { Makki and } \\
\text { Pop-Iliev, March } \\
2012[148,149]\end{array}$ \\
\hline Bending & $\begin{array}{l}\text { Piezoelectric (the } \\
\text { amount of the } \\
\text { harvested energy is } \\
\text { directly proportional } \\
\text { with tyre speed) }\end{array}$ & - & $\begin{array}{l}\text { Piezoresistiv } \\
\text { e pressure } \\
\text { sensor } \\
\text { (CPX100G) }\end{array}$ & - & $\begin{array}{l}\text { Attached } \\
\text { onto the } \\
\text { inner surface } \\
\text { of the tyre } \\
\text { belt }\end{array}$ & $\begin{array}{l}\text { Makki and } \\
\text { Pop-Iliev, } 2011 \\
{[59,150]}\end{array}$ \\
\hline $\begin{array}{l}\text { Cantilever beam } \\
\text { vibration } \\
\text { (oscillates in the } \\
\text { tangential } \\
\text { direction) }\end{array}$ & $\begin{array}{l}\text { Piezoelectric (the } \\
\text { amount of the } \\
\text { harvested energy is } \\
\text { inversely } \\
\text { proportional with } \\
\text { tyre speed) }\end{array}$ & $\begin{array}{l}\text { Contained } \\
\text { in a } \\
\text { traditional } \\
\text { TPMS } \\
\text { casing } \\
(40-60 \times \\
25-30 \times \\
8-10) \mathrm{mm}^{3}\end{array}$ & $\begin{array}{l}\text { LV Sensors' } \\
i \operatorname{TPS}^{\mathrm{TM}}\end{array}$ & $\begin{array}{l}\text { two-axis } \\
\text { accelerometer }\end{array}$ & $\begin{array}{l}\text { Fixed to the } \\
\text { tyre valve- } \\
\text { stem and sits } \\
\text { on the rim }\end{array}$ & $\begin{array}{l}\text { Atmel } \\
\text { Corporation, } \\
2008[20,151]\end{array}$ \\
\hline
\end{tabular}

Table 5. Summary of published research for energy harvesters designed potentially for self-powered TPMS.

\begin{tabular}{|c|c|c|c|c|c|c|}
\hline $\begin{array}{l}\text { Energy } \\
\text { Harvesting } \\
\text { Mechanism } \\
\end{array}$ & $\begin{array}{l}\text { Harvesting } \\
\text { Technique }\end{array}$ & Size & Power Output & Output Voltage & $\begin{array}{l}\text { Location } \\
\text { within the } \\
\text { Tyre }\end{array}$ & Source \\
\hline $\begin{array}{l}\text { Vibration } \\
\text { (floating magnet } \\
\text { oscillates inside } \\
\text { cylindrical coil) }\end{array}$ & $\begin{array}{l}\text { Electromagnetic } \\
\text { (the amount of the } \\
\text { harvested energy } \\
\text { is directly } \\
\text { proportional with } \\
\text { tyre speed) }\end{array}$ & $\begin{array}{l}5 \mathrm{~mm} \\
\text { diameter } \times \\
5 \mathrm{~mm} \text { high } \\
\text { magnet, no } \\
\text { more } \\
\text { specifications } \\
\text { are given }\end{array}$ & $\begin{array}{l}0.054 \mathrm{~mW} \text { at } 60 \mathrm{~km} / \mathrm{h} \\
\text { (by using a shaker to } \\
\text { simulate the harvested } \\
\text { energy, tyre size is not } \\
\text { specified) }\end{array}$ & $\begin{array}{l}1.5 \mathrm{VAC} \text { at } \\
60 \mathrm{~km} / \mathrm{h}\end{array}$ & $\begin{array}{l}\text { Attached onto the } \\
\text { inner surface of } \\
\text { the tyre belt }\end{array}$ & $\begin{array}{l}\text { Tornincas } \\
\text { a et al, } \\
2012 \text { [79] }\end{array}$ \\
\hline
\end{tabular}


Table 5. Cont.

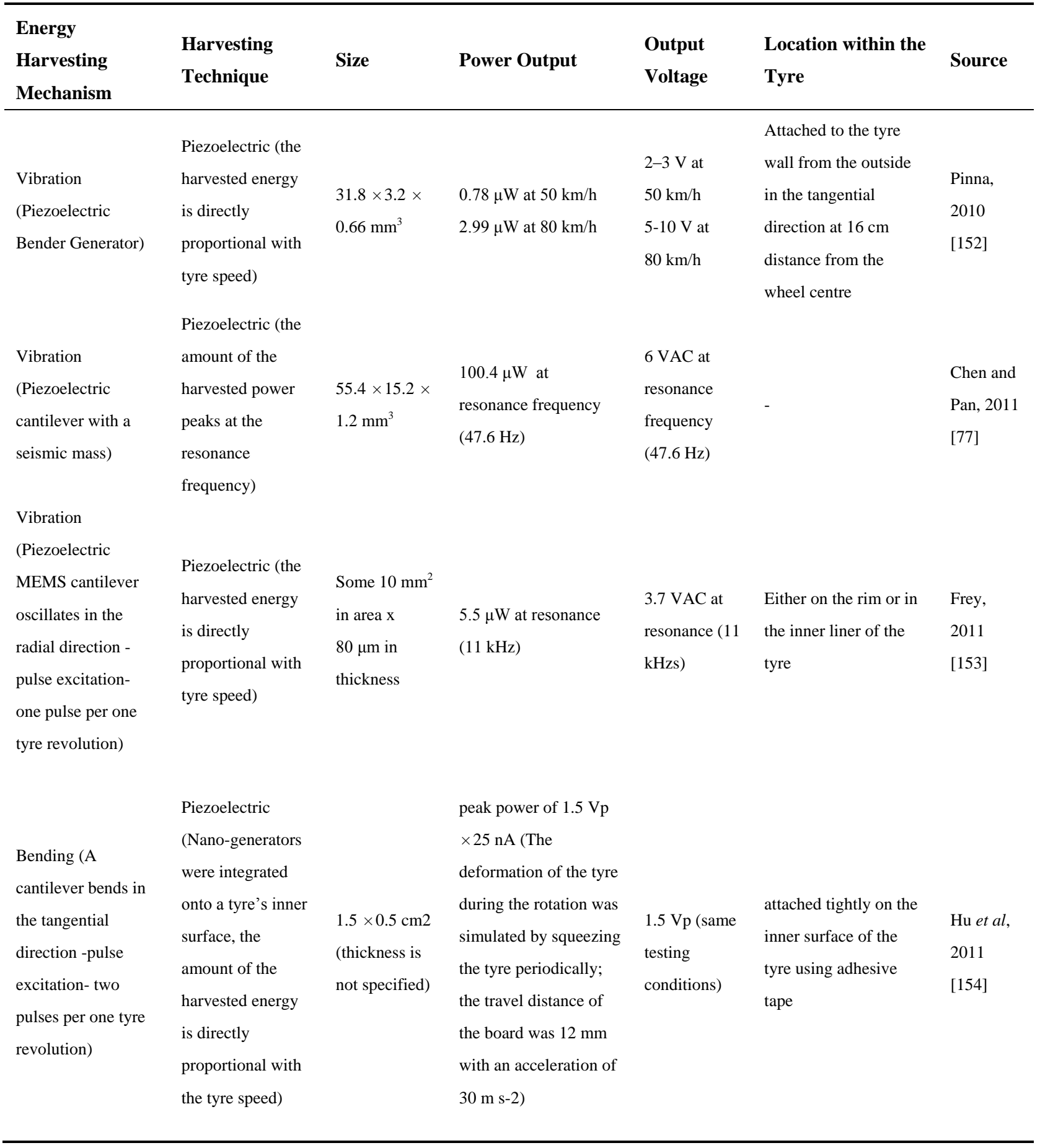


Table 5. Cont.

\begin{tabular}{|c|c|c|c|c|c|c|}
\hline $\begin{array}{l}\text { Energy } \\
\text { Harvesting } \\
\text { Mechanism }\end{array}$ & $\begin{array}{l}\text { Harvesting } \\
\text { Technique }\end{array}$ & Size & Power Output & $\begin{array}{l}\text { Output } \\
\text { Voltage }\end{array}$ & $\begin{array}{l}\text { Location within the } \\
\text { Tyre }\end{array}$ & Source \\
\hline $\begin{array}{l}\text { Vibration } \\
\text { (oscillation occurs } \\
\text { in the tangential } \\
\text { direction of the tyre) }\end{array}$ & $\begin{array}{l}\text { Electromagnetic } \\
\text { (A stacked magnet } \\
\text { oscillates along } \\
\text { the axis of a pick- } \\
\text { up coil, the } \\
\text { amount of the } \\
\text { harvested energy } \\
\text { varies with tyre } \\
\text { speed, however } \\
\text { the harvester } \\
\text { resonates at } 46 \\
\text { Hz) }\end{array}$ & $\begin{array}{l}30 \times 30 \times \\
11.7 \mathrm{~mm}^{3}\end{array}$ & $\begin{array}{l}0.144 \mathrm{~mW} \text { at } 50 \mathrm{~km} / \mathrm{h} \\
\text { at an acceleration of } 6 \\
\mathrm{~g}, \\
0.4 \mathrm{~mW} \text { at } 150 \mathrm{~km} / \mathrm{h} \text { at } \\
\text { an acceleration of } 15 \mathrm{~g} \\
\text { (by an arbitrary signal } \\
\text { generator to simulate } \\
\text { the harvested energy; } 1 \\
\mathrm{~Hz}=6.57 \mathrm{~km} / \mathrm{h} \text {, that is } \\
\text { for a } 57 \mathrm{~cm} \text { tyre } \\
\text { diameter) }\end{array}$ & $\begin{array}{l}120 \mathrm{mV} \text { at } \\
50 \mathrm{~km} / \mathrm{h} \text { at an } \\
\text { acceleration } \\
\text { of } 6 \mathrm{~g} \text {, } \\
200 \mathrm{mV} \text { at } \\
150 \mathrm{~km} / \mathrm{h} \text { at } \\
\text { an } \\
\text { acceleration } \\
\text { of } 15 \mathrm{~g} \\
\text { (across } \\
100 \Omega \\
\text { resister) }\end{array}$ & - & $\begin{array}{l}\text { Hatipoglu } \\
\text { and Urey, } \\
2009 \text { [75] }\end{array}$ \\
\hline $\begin{array}{l}\text { Vibration } \\
\text { (oscillation occurs } \\
\text { in the radial } \\
\text { direction of the tyre) }\end{array}$ & $\begin{array}{l}\text { Piezoelectric (a } \\
\text { both-side } \\
\text { supported beam } \\
\text { with non-linear } \\
\text { spring stiffness } \\
\text { central deflection) }\end{array}$ & $\begin{array}{l}\text { A diameter of } \\
10.4 \mathrm{~mm} \times \\
1.4 \mathrm{~mm} \\
\text { thickness }\end{array}$ & $\begin{array}{l}\text { Peak power }=80 \mu \mathrm{W} \\
\text { at } 80 \mathrm{~km} / \mathrm{h} \text {, average } \\
\text { power of } 40 \mu \mathrm{W} \text { over } \\
30-180 \mathrm{~km} / \mathrm{h} \text { speed } \\
\text { range }\end{array}$ & $\begin{array}{l}\text { Maximum of } \\
40 \mathrm{~V} \text { (open } \\
\text { circuit) } \\
\text { conditions } \\
\text { under which } \\
\text { this voltage is } \\
\text { obtained is } \\
\text { not specified }\end{array}$ & $\begin{array}{l}\text { The sensor module } \\
\text { mounted at the inner } \\
\text { tread area }\end{array}$ & $\begin{array}{l}\text { Keck, } \\
2007 \text { [74] }\end{array}$ \\
\hline $\begin{array}{l}\text { Vibration } \\
\text { (cantilever beam } \\
\text { structure) }\end{array}$ & $\begin{array}{l}\text { Piezoelectric } \\
\text { (three } \\
\text { piezoceramics in } \\
\text { parallel } \\
\text { connection) }\end{array}$ & Not specified & $\begin{array}{l}\text { Averaged power of } \\
0.38 \mathrm{~mW} \\
(3 \mathrm{~V} \text { regulated voltage } \\
\text { and current pulses of } \\
9.7 \mathrm{~mA} \text { which lasts for } \\
19.2 \mathrm{~ms} \text { per } 1423 \mathrm{~ms} \\
\text { across a resistor load } \\
\text { of } 3000 \Omega \text { ) }\end{array}$ & $\begin{array}{l}\text { Maximum } \\
12.3 \mathrm{~V} \text { at } \\
\text { resonance, } \\
125.8 \mathrm{~Hz} \\
\text { (open circuit) }\end{array}$ & - & $\begin{array}{l}\text { Liji Wu } \\
\text { et al, } \\
2009 \text { [69] }\end{array}$ \\
\hline $\begin{array}{c}\text { Vibration } \\
\text { (oscillation occurs } \\
\text { in the radial } \\
\text { direction) }\end{array}$ & $\begin{array}{l}\text { Piezoelectric (Air- } \\
\text { spaced cantilever, } \\
\text { the amount of the } \\
\text { harvested power } \\
\text { peaks at the } \\
\text { resonance } \\
\text { frequency) }\end{array}$ & $\begin{array}{c}15 \times 6 \times 46 \\
\mathrm{~mm}^{3}\end{array}$ & $\begin{array}{c}47 \mu \mathrm{W} \text { at } \\
\text { approximately } \\
80 \mathrm{~km} / \mathrm{h} \text { (resonance) }\end{array}$ & $\begin{array}{l}>5 \mathrm{VAC} \text { but } \\
\text { not specified }\end{array}$ & $\begin{array}{l}\text { The vibration energy } \\
\text { harvesting device was } \\
\text { mounted on the wheel } \\
\text { up-side-down to make } \\
\text { sure the PZT operates } \\
\text { in compression mode }\end{array}$ & $\begin{array}{c}\text { Zheng } \\
\text { et al, } \\
2009[70]\end{array}$ \\
\hline
\end{tabular}


Table 5. Cont.

\begin{tabular}{|c|c|c|c|c|c|c|}
\hline $\begin{array}{c}\text { Energy } \\
\text { Harvesting } \\
\text { Mechanism } \\
\end{array}$ & $\begin{array}{l}\text { Harvesting } \\
\text { Technique }\end{array}$ & Size & Power Output & $\begin{array}{l}\text { Output } \\
\text { Voltage }\end{array}$ & $\begin{array}{l}\text { Location within } \\
\text { the Tyre }\end{array}$ & Source \\
\hline $\begin{array}{l}\text { Vibration } \\
\text { (pendulum-driven } \\
\text { self-tuning energy } \\
\text { harvester oscillates } \\
\text { in the tyre } \\
\text { tangential direction) }\end{array}$ & $\begin{array}{l}\text { Piezoelectric } \\
\text { (Pendulum impact } \\
\text { harvester in which } \\
\text { its ball impacts } \\
\text { the PZT beam, the } \\
\text { amount of the } \\
\text { harvested energy } \\
\text { is directly } \\
\text { proportional with } \\
\text { the angular speed) }\end{array}$ & $\begin{array}{c}(\approx 10) \times 20 \times \\
20 \mathrm{~mm}^{3}\end{array}$ & $\begin{array}{c}123 \mu \mathrm{W} \text { at } 16.2 \mathrm{~Hz} \\
60 \mu \mathrm{W} \text { at } 6.2 \mathrm{~Hz}\end{array}$ & $\begin{array}{l}(21-25) \mathrm{V}_{\mathrm{p}-\mathrm{p}} \\
\text { over the } \\
\text { frequency } \\
\text { range } \\
(4-16) \mathrm{Hz} \text { in } \\
\text { which the } \\
\text { system } \\
\text { almost } \\
\text { remains at } \\
\text { resonance }\end{array}$ & $\begin{array}{l}\text { The device is mounted } \\
\text { at optimal radius of } 7.5 \\
\mathrm{~mm} \text { from the centre of } \\
\text { rotation }\end{array}$ & $\begin{array}{c}\text { Lei Gu, } \\
\text { and } \\
\text { Livermor } \\
\text { e, 2010 } \\
\text { [155] }\end{array}$ \\
\hline $\begin{array}{l}\text { Vibration (non- } \\
\text { contact frequency } \\
\text { up-conversion } \\
\text { piezoelectric } \\
\text { harvester based on } \\
\text { magnetic repulsive } \\
\text { force oscillates in } \\
\text { the tyre tangential } \\
\text { direction) }\end{array}$ & $\begin{array}{l}\text { Piezoelectric ( } 2 \\
\text { cantilevers excited } \\
\text { by magnetic } \\
\text { repulsive force) }\end{array}$ & Not clear & $\begin{array}{l}\text { Average power of } 10 \\
\mu \mathrm{W} \text { over the frequency } \\
\text { range }(10-22) \mathrm{Hz} \\
\text { under } 1 \mathrm{~g} \text { acceleration } \\
\text { of excitation }\end{array}$ & $\begin{array}{c}\text { Average } \\
\text { voltage } \approx \\
14 \mathrm{~V}_{\mathrm{p}-\mathrm{p}} \text { across } \\
\mathrm{a} \\
6.1 \mathrm{M} \Omega \\
\text { resistive load }\end{array}$ & $\begin{array}{l}\text { The harvester mounted } \\
\text { on the rim inside the } \\
\text { tyre cavity }\end{array}$ & $\begin{array}{c}\text { Tang } \\
\text { et al, } \\
2012[72]\end{array}$ \\
\hline $\begin{array}{l}\text { Vibration } \\
\text { (oscillation occurs } \\
\text { in the tyre } \\
\text { tangential direction) }\end{array}$ & $\begin{array}{l}\text { Piezoelectric } \\
\left(\text { Thunder }{ }^{\mathrm{TM}}\right. \\
\text { piezoelectric } \\
\text { generator) }\end{array}$ & $2 \mathrm{~cm}^{3}$ & $\begin{array}{c}4 \mathrm{~mW} \text { at } 800 \mathrm{rpm} \text { (by } \\
\text { using a } 0.12 \mathrm{~m} \\
\text { diameter test wheel; } \\
\text { equivalent to a vehicle } \\
\text { wheel with a diameter } \\
\text { of } 13 \text { inches and a } \\
\text { linear speed of } \\
45.44 \mathrm{~km} / \mathrm{h} \text { ) }\end{array}$ & $\begin{array}{l}\text { Pulses of up } \\
\text { to } 150 \mathrm{~V}_{0-\mathrm{p}}\end{array}$ & $\begin{array}{l}\text { To be mounted on the } \\
\text { rim (the energy } \\
\text { harvester was kept in } \\
\text { horizontal position } \\
\text { while wheel rotation is } \\
\text { in a vertical plane }\end{array}$ & $\begin{array}{c}\text { Manl } \\
\text { et al, } \\
2009[16]\end{array}$ \\
\hline $\begin{array}{l}\text { Vibration (a } \\
\text { weighted-pendulum } \\
\text { which oscillate in } \\
\text { the rotation plane) }\end{array}$ & $\begin{array}{c}\text { Electromagnetic } \\
\text { (eight permanent } \\
\text { magnets in a disk } \\
\text { shape, allocated in } \\
\text { a ring, and eight } \\
\text { corresponding } \\
\text { coils in series are } \\
\text { fixed on the } \\
\text { wheel) }\end{array}$ & $\begin{array}{l}\approx 2.5 \mathrm{~cm} \text { in } \\
\text { diameter, } \\
\text { thickness is } \\
\text { not specified }\end{array}$ & $\begin{array}{l}\text { Average power of } 349 \\
\mu \mathrm{W} \text { at } 400 \mathrm{rpm} \text { across } \\
\text { a } 330 \Omega \text { resistive load }\end{array}$ & $\begin{array}{c}\approx 0.33 \mathrm{~V}_{\text {rms }} \text { at } \\
400 \mathrm{rpm} \\
\text { across a } 330 \\
\Omega \text { resistive } \\
\quad \text { load }\end{array}$ & $\begin{array}{l}\text { The weighted } \\
\text { pendulum combined } \\
\text { with magnets and coils } \\
\text { was mounted on a } \\
\text { rotation plate driven } \\
\text { by an AC servo motor } \\
\text { to simulate the device } \\
\text { oscillation. }\end{array}$ & $\begin{array}{c}\text { Wang } \\
\text { et al, } \\
2012[73]\end{array}$ \\
\hline
\end{tabular}

\section{Battery-Less TPMS Industry}

Virtually all the commercially available TPMSs are battery powered and designed to be mounted on the rim or fixed to the tyre valve. However, some companies are currently working on developing a 
battery-free TPMS. For instance, Transense Technologies plc is using a surface acoustic wave (SAW) based technology, in addition to companies such as Honeywell (Weybridge,UK) and Michelin (Greenville, SC, USA). SAW systems measure pressure with temperature compensation and can either be attached to the wheel (e.g., back of valve or to run-flat system), embedded in the wheel or it can be attached to the tyre itself $[3,139,156]$. On the other hand, Visityre (East Kalara, Australia) is using an electromagnetic closed-coupling technology. In this design, relatively large hardware is needed to be installed in the tyre brake structure [3,137,157]. The Hong Kong Applied Science and Technology Research Institute Company Ltd. (ASTRI, Hong Kong) have recently developed a piezoelectric vibration-based energy harvesting TPMS. Although the specification of this device is not precisely clear, ASTRI claims that the commercial model of this device can be reduced in size to $2.5 \times 2.5 \mathrm{~cm}[3,158]$. Eoplex is also developing a vibration energy harvester. This company focuses only on producing the energy harvester to be used in energy scavenging based TPMS systems as a power supply [3,159]. Perilli (Milan, Italy), in collaboration with Schrader Electronics Ltd. (Antrim, UK), under the Cyber Tire Lean project, has developed a tyre monitoring system, approximately $24 \mathrm{~mm}$ in diameter with a flexible rubber base, that can be attached to the inside surface of the tyre. The system is capable of measuring pressure, temperature, the average load supported by each wheel and speed, sending the information directly to the electronic control unit of the vehicle the device harvests energy through tyre mechanical vibration and supplies the collected energy to the device circuitry [160]. Siemens VDO (Regensburg, Germany), now Continental, collaborating with Goodyear Tyre and Rubber Co. (Akron, $\mathrm{OH}$, USA), has developed a TPMS that can be mounted in the tyre's rim. The device is powered by a piezoelectric based vibration energy harvester. The manufacturer claims that this device is capable of transmitting data every $60 \mathrm{~s}$ or less [160]. In vibration-based energy harvesting systems, there are two main inescapable problems. Firstly, these systems need to operate at a particular value of vibration frequency in order to achieve optimum performance. Otherwise, a slight difference in the vibration frequency decreases the efficiency of this vibration system dramatically. The second problem is the size and weight issues with these systems (energy density), if a reasonable amount of power generation is required [78]. Piezotag has developed a TPMS which can be mounted on the inside surface of the tyre and it harvests energy from tyre deformation, particularly bending [3,161].

\section{Conclusions and Discussion}

The literature review began with the history of pneumatic tyres and how they evolved to their current form in which the inflation pressure is a crucial factor for safety and durability. There are wireless devices that can monitor tyre inflation pressure and other conditions when necessary in real time. Then a survey of all the essential components that are needed to build a TCMS was carried out. Following this there was a review of different types of pressure sensing mechanisms, making a comparison between them, and choosing the mechanism that meets the self-powered TCMS requirements. Then the necessity to solve the energy source problem for powering tyre monitoring systems, particularly inflation pressure monitoring, was presented. Following this various harvestable energy sources in a rolling tyre were discussed, kinetic energy, strain energy, and thermal energy. Then an overview of the existing energy harvesting techniques, e.g., piezoelectric, electromagnetic, electrostatic, and thermoelectric, that can be applied within the tyre-rim assembly was given and 
compared, in order to choose the most appropriate technique that meets the power requirements for the TCMS and that can withstand the tyre cavity harsh conditions. Following this different means of power management techniques in order to store and condition the harvested energy were presented. Finally a survey of the existing battery-less TPMS, self-powered TPMS, and energy harvesting devices which are based on scavenging energy from a rolling tyre, were presented. The general TPMS requirements are shown in Table 6. These requirements are used as design criteria for the tyre monitoring system to be developed in this research project.

It has been found that the least power hungry pressure sensor is the capacitive type, and therefore a design incorporating this type of pressure sensor is needed in this study.

In terms of harvesting the energy required to power the TCMS, it has been found that the most efficient technique is harvesting strain energy in the tyre, which is generated by cyclic tyre deformation, directly; that is by applying a piezoelectric element onto the inner tyre liner in an appropriate position. A vibration based energy harvesting system utilizing a weighted cantilever system or an electromagnetic system could also be efficient. However the drawbacks of these systems are a narrow response frequency for useful power generation and an increase in system mass resulting in lower power density.

Table 6. TCMS requirements and design criteria.

\begin{tabular}{|c|c|}
\hline TPMS Type & Active and Direct \\
\hline Power supply & Energy harvesting technique \\
\hline Energy harvester & $\begin{array}{l}\text { To operate efficiently and to generate sufficient energy to power } \\
\text { the TCMS. The harvester is intended to last the lifetime of the } \\
\text { tyre ( } 20 \mathrm{k}-40 \mathrm{k} \text { miles) }\end{array}$ \\
\hline Operating temperature & $-40^{\circ} \mathrm{C}$ to $125^{\circ} \mathrm{C}$ \\
\hline Pressure monitoring range & 0 to 3 bars $(0$ to $300 \mathrm{kPa})$ \\
\hline Operating frequency & $2.4 \mathrm{GHz}$ \\
\hline Pressure reading accuracy & $\pm 7 \mathrm{kPa}( \pm 1 \mathrm{psi})$ \\
\hline Temperature reading accuracy & $\pm 1{ }^{\circ} \mathrm{C}$ \\
\hline Transmission power & $0-5 \mathrm{dBm}$ \\
\hline Voltage & $3.6 \mathrm{~V}$ \\
\hline Power consumption & Less than $250 \mu \mathrm{W}$ \\
\hline Duty cycle & $\begin{array}{l}\text { To report faulty tyre pressure (reduction of up to } 20 \% \text { of } \\
\text { inflation pressure) after no more than } 10 \text { minutes from detecting } \\
\text { it and to transmit tyre pressure reading within not more than } 60 \\
\text { minutes of cumulative driving (by summing up time while } \\
\text { vehicle speed is larger than } 40 \mathrm{~km} / \mathrm{h} \text { ) [162] }\end{array}$ \\
\hline Sensor weight & Less than $35 \mathrm{~g}$ \\
\hline Reception unit & USB unit plugged to a portable laptop \\
\hline Installation & To be affixed to the tyre valve stem inside the tyre cavity \\
\hline
\end{tabular}

Experimental tyre strain measurements and profiles obtained by other studies $[58,65,163,164]$ have been used to estimate the amount of electric charge generated when a piezoelectric material is attached to an inner tyre surface. The only limitation, however, is excessive tyre strain. This means an 
appropriate adhesive has to be used to keep the piezoelectric harvester functional and to prevent permanent damage.

Different types of TPMSs are reviewed in this article. Active TPMS means that the system has its own power source, which can be either a battery or an energy harvesting based power source. On the other hand, a passive TPMS is driven remotely and therefore no direct connection with its power source exists. This makes passive TPMSs not well suited for low power consumption purposes as transferring power wirelessly is not an efficient process. For this reason, active TPMS approach is targeted in this research. TPMS pressure sensing approaches are also reviewed in this article. There are three main pressure sensing methods; direct, indirect and hybrid, among which Direct TPMS offers the greatest accuracy and the quickest possible response. For these reasons, direct TPMS is targeted in this research.

The major power sources for active TPMSs are reviewed in this article. It was found from the literature that batteries are the predominant power supply for TPMS devices for their low cost and high power density. Batteries however have considerable downsides which are their limited life time and subsequently environmental disposal problem. Therefore energy harvesting is targeted in this research. High energy density and power conversion efficiency are crucial factors to power the targeted TCMS. The main energy harvesting techniques observed in the literature are electromagnetic, electrostatic, piezoelectric and thermal energy harvesting means. The output signal characteristics (voltage and current) are also required to be within a range that is possibly adaptable by the existing power management chips. The best candidate among the major energy harvesting techniques which meets the selection criteria is the piezoelectric energy harvesting technique, and therefore research is focused on this type of energy harvesters.

In the literature, it has also been found that an appropriate circuitry has to be built to maximize the collectable harvested energy efficiently, and therefore an electronic circuit for power management, data measurements, and wireless transmission purposes is needed in this study. The circuit design is driven by electronic chips available on the market today and could possibly evolve over the study period depending on any new related electronic chips which are developed.

There are several mechanisms to employ piezoelectric transducer as energy harvesters, two among which are of interest in this research; vibration and direct strain energy harvesting mechanisms. In the literature, vibration energy harvesting approach is the dominant approach for piezoelectric-based energy harvesting devices, including TPMS related research, due to its simplicity to assemble, to model, and to affix to vibration sources. Direct strain energy harvesting approach is an attractive way to harvest energy, besides it is easier to model. However the literature lacks experimental investigation for such harvesting mechanism, particularly in rolling tyres. Further exploration for vibration and direct strain energy harvesting mechanisms in a rolling tyre was found to be needed to determine which method suits powering TPMS best. For this reason, comparison between vibration and direct strain energy harvesting for powering TPMS purposes is addressed in this research.

\section{Acknowledgments}

This work was supported by the Engineering and Physical Sciences Research Council, the Technology Strategy Board (grant number 11200-73308), and the University of Birmingham. 


\section{Conflicts of Interest}

The authors declare no conflict of interest.

\section{References}

1. TNO, IEEP, and a. LAT. Review and Analysis of the Reduction Potential and Costs of Technological and other Measures to Reduce $\mathrm{CO}_{2}$-emissions from Passenger Cars; Final report, Contract No. SI2.408212; Delft, the Netherlands, 31 October 2006.

2. Transense. SAW Based Tyre Pressure Monitoring System. Available online: http://www.transense.co.uk/technologies/temppressure/motorsport-tpms (accessed on 16 December 2011).

3. Zervos, H. Tyre pressure monitoring systems and energy harvesting. Available online: http://www.energyharvestingjournal.com/articles/tyre-pressure-monitoring-systems-and-energyharvesting-00002587.asp?sessionid=1 (accessed on 7 October 2011).

4. Spectrum Batteries Inc., Lithium/Thionyl Chloride Batteries-180C. Available online: http://www.etv.com.au/Thionyl180msds.pdf (accessed on 16 December 2011).

5. VisiTyre Automotive PL, The Problems with Batteries in TPMS, Safety and Environmental Concerns, in DMS 02062009 Battery Environmental Concerns. Available online: http://www.etv.com.au/Safety_Environmental.pdf (accessed on 16 December 2011).

6. Delta Electronics Inc., Electromagnetic coupling. Available online: http://www.delta.com.tw/ product/ap/tpms/tpms_main.asp (accessed on 16 December 2011).

7. David, S.; Alex, B.; Gaby, L.; Pedder, S. Trends in the Global Tire Industry. SupplierBusiness: MA, USA, June 2011.

8. Title 49 United States Code 30101, Transportation Recall Enhancement, Accountability, and Documentation (TREAD) Act, Volume: Public Law 106-414-NOV.1, 106th Congress: OH, USA, 2000.

9. Smith, J.A.; Moore, J.S.; Holmbraker, S.; Bartlett, A.J.; Campbell, W.A. Tiresafe Product Overview; Volume: NHTSA-00-8572-1; National Highway Traffic Safety Administration: New Jersey, NJ, USA, 2000.

10. Mazzae, E.N.; Ranney, T.A. Development of an Automotive Icon for Indication of Significant Tire Underinflation. Proc. Human Factors Ergonom. Soc. Annual Meet. 2001, doi:10.1177/154193120104502317.

11. Grygier, P.; Garrott, W.R.; Mazzae, E.N.; MacIssac, J.D. Jr.; Hoover, R.L.; Elsasser, D.; Ranney, T.A. An evaluation of existing tire pressure monitoring systems; Volume: DOT 809 297; National Highway Traffic Safety Administration: Jersey, NJ, USA, July 2001.

12. MacIsacc, J.D.J.; Garott, W.R. Preliminary findings of the effect of tire inflation pressure on the peak and slide coefficients of friction; Volume:DOT 809428; National Highway Traffic Safety Administration: Jersey, NJ, USA, June 2002.

13. Federal motor vehicle safety standards; tire pressure monitoring systems; controls and displays; Volume: NHTSA-2000-8572; National Highway Traffic Safety Administration: Jersey, NJ, USA, 2000. 
14. Federal motor vehicle safety standards; tire pressure monitoring systems; controls and displays; Volume: NHTSA-2005-20586; National Highway Traffic Safety Administration: Jersey, NJ, USA, 2005.

15. Fleming, B. Tire pressure-monitoring systems rollout (Automotive Electronics). IEEE Veh. Technol. Mag. 2009, 4, 6-10.

16. Manla, G.; White, N.M.; Tudor, J. Harvesting energy from vehicle wheels. In Proceedings of the Solid-State Sensors, Actuators and Microsystems Conference, Denver, CO, USA, 21-25 June 2009.

17. Onoda, T. IEA policies-G8 recommendations and an afterwards. Energy Policy 2009, 37, 3823.

18. Rui, X.H.; Jin, Y.; Feng, X.Y.; Zhang, L.C.; Chen, C.H. A comparative study on the low-temperature performance of $\mathrm{LiFePO}_{4} / \mathrm{C}$ and $\mathrm{Li}_{3} \mathrm{~V}_{2}\left(\mathrm{PO}_{4}\right)^{3} / \mathrm{C}$ cathodes for lithium-ion batteries. J. Power Sources 2010, 196, 2109.

19. Zhang, S.S.; Xu, K.; Jow, T.R. The low temperature performance of Li-ion batteries. J. Power Sources 2003, 115, 137.

20. Roundy, S. Energy Harvesting for Tire Pressure Monitoring Systems, Design Considerations. In Proceedings of the Power MEMS + microMEMS, Sendai, Japan, 9-12 November 2008.

21. Löhndorf, M.; KvisterØy, T.; Westby, E.; Halvorsen, E. Evaluation of Energy Harvesting Concepts for Tire Pressure Monitoring Systems. In Proceedings of the Technical Digest PowerMEMS 2007, Freiburg, Germany, 28-29 November 2007; pp. 331-334.

22. Rudolf, S.S.F.; Hoogerwerf, A. Components for battery-powered wireless tire pressure and temperature monitoring systems. In Proceedings of the SensorExpo Detroi, NH, USA, 23 October 1997; pp. 15-20.

23. Flatscher, M.; Dielacher, M.; Herndl, T.; Lentsch, T.; Matischek, R.; Prainsack, J.; Pribyl, W.; Theuss, H.; Weber, W. A robust wireless sensor node for in-tire-pressure monitoring. In Proceedings of the Solid-State Circuits Conference-Digest of Technical Papers, Sanfrancisco, CA, USA, 8-12 February 2009.

24. Zhang, J.; Chen, T.; Kong, X.M.; Ren, T.L.; Liu, L.T. A Tire Pressure Monitoring System Based on MEMS Sensor. Key Eng. Mater. 2011, 483, 370-373.

25. Tompkins, E.P. Dunlop Archive, the History of the Pneumatic Tyre; Lavnhampress LTD Press: Suffolk, UK, 1981.

26. Gillespie, T.D. Fundamentals of Vehicle Dynamics; Society of Automotive Engineers: Pennsylvania, PA, USA, 1992.

27. Thurau, J.; Ruohio, J. Silicon Capacitive Absolute Pressure Sensor Elements for Battery-less and Low Power Tire Pressure Monitoring; In Advanced Microsystems Automotive Applications, Jürgen, V., Gessner, W., Eds., Springer: New York, NY, USA, 2004; p. 109.

28. Velupillai, S.; Guvenc, L. Tire Pressure Monitoring (Applications of Control). IEEE Contr. Syst. 2007, 27, 22.

29. Walter, R.; Salzinger, T. Final report, Motor vehicle tyres and related aspects, TÜV Automotive GmbH; The European Commision Enterprise Directorate Genaral: Flensburg, Germany, 2003.

30. Steckelmacher, W. A review of low pressure measurement from an industrial viewpoint. J. Sci. Instrum. 1965, 42, 63.

31. Strangeways, I. Back to basics: The "met. enclosure": Part 8(b) -Barometric pressure, aneroid barometers. Weather 2002, 57, 204. 
32. Hunt, L.B. The History of Pressure Responsive Elements. J. Sci. Instrum. 1944, 21, 37-42.

33. Tang, Y.U. Michigan State, Polycrystalline diamond (poly-C) technology and piezoresistive sensor application for cochlear prosthesis. Michigan State University: Ann Arbor, MI, USA, 2007.

34. Busch-Vishniac, I.J. Electromechanical Sensors and Actuators; Springer: Baltimore, MD, USA, 1999.

35. Eaton, W.P.; Smith, J.H. Micromachined pressure sensors: Review and recent developments. Smart Mater. Struct. 1997, 6, 530-539.

36. Anand, K.B.; Kulkarni, V.A. Metrology \& Measurement; McGraw-Hill Education (India) Pvt Ltd.: New Delhi, India, 2009.

37. Eddy, D.S.; Sparks, D.R. Application of MEMS technology in automotive sensors and actuators. Proc. IEEE 1998, 86, 1747.

38. Barlian, A.A.; Park, W.T.; Mallon, J.R.; Rastegar, A.J.; Pruitt, B.L. Review: Semiconductor Piezoresistance for Microsystems. Proc. IEEE 2009, 97, 513.

39. Beeby, S.; Ensell, G.; Kraft, M.; White, N. MEMS Mechanical Sensors; Artech House Publishers: Norwood, MA, USA, 2004.

40. Gad-el-Hak, M. The MEMS Handbook; CRC Press: Boca Raton, FL, USA, 2002.

41. Madhavi, K.Y.; Sumithradevi, K.A.; Krishna, M.; Vijayalakshmi, M.N. Analysis of Square and Circular Diaphragms for a MEMS Pressure Sensor Using a Data Mining Tool. In Proceedings of the International Conference on Communication Systems and Network Technologies (CSNT), Jammu, India, 3-5 June 2011; pp. 258-261.

42. Khakpour, R.; Mansouri, S.; Bahadorimehr, A.R. Analytical comparison for square, rectangular and circular diaphragms in MEMS applications. In Proceeding of International Conference on Electronic Devices, Systems and Applications (ICEDSA), Kuala Lumpur, Malaysia, 11-14 April 2010; pp. 297-299.

43. Hermann, S. Low-pressure sensor with bossed diaphragm. Mechatronics 1991, 1, 393.

44. Cavalloni, C.; Berg, J.; Krueger, S.; Gessner, W. Overview: Principles and Technologies for Pressure Sensors for Automotive Applications. In Advanced Microsystems for Automotive Applications Yearbook 2002; Springer: Berlin, Heidelberg, Germany, 2002; p. 232.

45. Kinnell, P.K. The development of selective strain coupling structures for a novel MEMS resonant pressure sensor; Ph.D. Thesis, The University of Birmignham: Birmingham, UK, 2005.

46. Wang, Q.; Ko, W.H. Modeling of touch mode capacitive sensors and diaphragms. Sens. Actuators A Phys. 1999, 75, 230.

47. Wei-Zang, C.; Li-zhou, P.; Xiao-ming, L. Large deflection problem of a clamped elliptical plate subjected to uniform pressure. Appl. Mathem. Mech. 1992, 13, 891.

48. Timoshenko, S. Theory of Plates and Shells; 1st ed.; McGraw-Hill: New York, NY, USA, 1940.

49. Roundy, S.J. Energy Scavenging for Wireless Sensor Nodes with a Focus on Vibration to Electricity Conversion. Ph.D. Thesis, University of California, Berkeley, USA, Spring 2003.

50. Worthington, E.L. Piezoelectric Energy Harvesting: Enhancing Power Output by Device Optimisation and Circuit Techniques, in School of Applied Sciences Microsystems and Nanotechnology Centre. Ph.D. Thesis, Cranfield University: Cranfield, UK, 30 August 2010.

51. Chalasani, S.; Conrad, J.M. A survey of energy harvesting sources for embedded systems. In Proceedings of the IEEE Southeastcon, Huntsville, AL, USA, 3-6 April 2008; pp. 442-447. 
52. Cook-Chennault, K.A.; Sastry, A.M.; Thambi, N. Topical review: Powering MEMS portable devices-a review of non-regenerative and regenerative power supply systems with special emphasis on piezoelectric energy harvesting systems. Institute of Physics Publication: Bristol, UK, 2008.

53. Knight, C.; Davidson, J.; Behrens, S.B. Energy Options for Wireless Sensor Nodes. Sensors 2008, 8, 8037-8066.

54. Knight, C.; Davidson, J.; Mukhopadhyay, S.C.; Leung, H. Thermal Energy Harvesting for Wireless Sensor Nodes with Case Studies. In Advances in Wireless Sensors and Sensor Networks; Springer: Berlin/Heidelberg, Germany, 2010; pp. 221-242.

55. Wang, D.A.; Pham, H.T.; Chao, C.W.; Chen, J.M. A Piezoelectric Energy Harvester Based on Pressure Fluctuations in Kármán Vortex Street. In Proceedings of the World Renewable Energy Congress 2011, Hydropower Applications (HP)-Sweden, Linköping, Sweden, 8-13 May 2011.

56. Knight, C.; Davidson, J. Thermoelectric energy harvesting as a wireless sensor node power source. In Proceedings of the Active and Passive Smart Structures and Integrated Systems 2010, San Diego, CA, USA, 8 March 2010.

57. Ende, D.A.V.D.; Wiel, H.J.V.D.; Groen, W.A.; Zwaag, S.V.D. Direct strain energy harvesting in automobile tires using piezoelectric PZT-polymer composites. Smart Mater. Struct. 2011, 21, $1-11$.

58. APOLLO. Final Report, Intelligent Tyre for Accident-Free Traffic. Technical Research Centre of Finland (VTT); IST-2001-3437; Tampere, Finland, 2005.

59. Makki, N. Piezoelectric power generation in automotive tires. In Proceedings of the Smart Materials \& Structures/NDT in Aerospace/NDT in Canada 2011, Montreal, QC, Canada, 2-4 November 2011.

60. Jingang, Y. A Piezo-Sensor-Based "Smart Tire" System for Mobile Robots and Vehicles. IEEE/ASME Trans. Mechatr. 2008, 13, 95.

61. J. Holtschulze, H. Goertz, and T. semann, "A simplified tyre model for intelligent tyres," Vehicle System Dynamics, vol. 43, pp. 305, 2005.

62. Ryosuke, M.; Naoki, H.; Todoroki, A.; Mizutani, Y. Analysis of Applied Load Estimation Using Strain for Intelligent Tires. J. Solid Mech. Mater. Eng. 2010, 4, 1496-1510.

63. Hall, J.T.M.W.; Jones, R.P. Finite element simulation of a rolling automobile tyre to understand its transient macroscopic behavior. In Proceedings of the Institution of Mechanical Engineers. J. Automob. Eng. 2004, 218, 1393-1408.

64. Pottinger, M.G. The three dimensional contact patch stress field of solid and pneumatic tires. Tire Sci. Technol. 1992, 20, 3.

65. Yang, X. Finite Element Analysis and Experimental Investigation of Tyre Characteristics for Developing Strain-Based Intelligent Tyre System, in Mechanical Engineering, Ph.D. Thesis, Birmingham: University of Birmingham, Birmingham, UK, September 2011, p. 220.

66. Gardner, J.D.; Queise, B.J. Introduction to Tire Safety, Durability and Failure Analysis. In The Pneumatic Tire; National Highway Traffic Safety Administration: DC, USA, 2006; pp. 618-640.

67. Braghin, F.; Brusarosco, M.; Cheli, F.; Cigada, A.; Manzoni, S.; Mancosu, F. Measurement of contact forces and patch features by means of accelerometers fixed inside the tire to improve future car active control. Veh. Syst. Dyn. 2006, 44, 3. 
68. Kindt, P.; Sas, P.; Desmet, W. Measurement and analysis of rolling tire vibrations. Opt. Lasers Eng. 2009, 47, 443.

69. Liji, W.; Yixiang, W.; Chen, J.; Chun, Z. Battery-less piezoceramics mode energy harvesting for automobile TPMS. In Proceedings of the IEEE 8th International Conference on ASIC, Changsha, China, 20-23 October 2009; pp. 1205-1208.

70. Zheng, Q.; Tu, H.; Agee, A.; Xu, Y. Vibration Energy Harvesting Device Based on Asymmetric Air-Spaced Cantilevers for Tire Pressure Monitoring System. In Proceedings of the Power MEMS 2009, Washington, DC, USA, 1-4 December 2009; pp. 403-s406.

71. Gu, L.; Livermore, C. Compact passively self-tuning energy harvesting for rotating applications. Smart Mater. Struct. 2011, 21, 015002.

72. Tang, Q.C.; Xia, X.Y.; Li, X.X. Non-contact frequency-up-conversion energy harvester for durable \&amp; broad-band automotive TPMS application. In Proceedings of the 2012 IEEE 25th International Conference on Micro Electro Mechanical Systems (MEMS), Paris, France, 29 January-2 February 2012; pp. 1273-1276.

73. Wang, Y.J.; Chen, C.D.; Sung, C.K. System Design of a Weighted-Pendulum-Type Electromagnetic Generator for Harvesting Energy From a Rotating Wheel. IEEE/ASME Trans. Mechat. 2012, 18, 754-763.

74. Keck, M. A new approach of a piezoelectric vibration-based power generator to supply next generation tire sensor systems. In Proceedings of the 2007 IEEE Sensors, Atlanta, GA, USA, 28-31 October 2007; pp. 1299-1302.

75. Hatipoglu, G.; Urey, H. FR4-based electromagnetic energy harvester for wireless tyre sensor nodes. Procedia Chem. 2009, 1, 1211.

76. Suzuki, Y. Recent progress in MEMS electret generator for energy harvesting. IEEE Trans. Electr. Electr. Eng. 2011, 6, 101.

77. Chen, Y.-Y.; Pan, H.-W. A Piezoelectric Vibration Energy Harvester for Tire Pressure Monitoring Systems. In Proceedings of the Symposium on Ultrasonic Electronics, Kyoto, Japan, 8-10 November 2011; pp. 321-322.

78. Luigi, P.; Maurizio, V.; Bo, G.M. Experimental results of piezoelectric bender generators for the energy supply of smart wireless sensors. In Proceedings of the Sensors and Microsystems, Roma, Italy, 19-22 February 2008; pp. 450-458.

79. Tornincasa, S.; Repetto, M.; Bonisoli, E.; Monaco, F.D. Energy harvester for vehicle tires: Nonlinear dynamics and experimental outcomes. J. Intell. Mater. Syst. Struct. 2012, 23, 3-13.

80. Farbod, K.; Siamak, A. Energy Harvesting from Pneumatic Tires Using Piezoelectric Transducers. ASME Conf. Proc. 2008, 2008, 331-337.

81. Tsujiuchi, N.; Koizumi, T.; Oshibuchi, A.; Shima, I. Rolling Tire Vibration Caused by Road Roughness. In Proceedings of SAE 2005 Noise and Vibration Conference and Exhibition, Traverse City, MI, USA, 16 May 2005.

82. Clark, S.K.; Dodge, R.N. A handbook for the rolling resistance of pneumatic tires. University of Michigan: Ann Arbor, MI, USA, 1979.

83. Gusakov, I. Laboratory Measurements of Tire Rolling Resistance under Simulated Driving Cycles. In Proceedings of the Tire rolling losses and fuel economy: An R \& D Planning Workshop, Cambridge, MA, USA, 1977. 
84. Wilburn, D.K. A temperature study of pneumatic tires during highway operation: Defense Technical Information Center, Belvoir, VA, USA, 1972.

85. Narasimha, K.V.; Rao, R.K.; Kumar, P.C.; Mukhopadhyay, R. A Finite Element Algorithm for the Prediction of Steady-State Temperatures of Rolling Tires. Tire Sci. Technol. 2006, 34, 195.

86. Yeong-Jyh, L.; Sheng-Jye, H. Temperature prediction of rolling tires by computer simulation. Math. Comput. Simul. 2004, 67, 235-249.

87. Zepeng, W. Finite Element Analysis of Mechanical and Temperature Field for a Rolling Tire. In Proceedings of the 2010 International Conference on Measuring Technology and Mechatronics Automation-Volume 02: IEEE Computer Society. Changsha, China, 13-14 March 2010.

88. Ebbott, T.G.; Hohman, R.L.; Jeusette, J.â.P.; Kerchman, V. Tire Temperature and Rolling Resistance Prediction with Finite Element Analysis. Tire Sci. Technol. 1999, 27, 2.

89. Bouendeu, E.; Greiner, A.; Smith, P.J.; Korvink, J.G. A Low-Cost Electromagnetic Generator for Vibration Energy Harvesting. IEEE Sens. J. 2011, 11, 107-113.

90. Saha, C.R.; O'Donnell, T.; Loder, H.; Beeby, S.; Tudor, J. Optimization of an Electromagnetic Energy Harvesting Device. IEEE Trans. Magnet. 2006, 42, 3509.

91. Beeby, S.P.; O’Donnell, T.; Priya, S.; Inman, D.J. Electromagnetic Energy Harvesting. In Energy Harvesting Technologies; Springer: Blacksburg, VA, USA, 2009; p. 129.

92. Amirtharajah, R.; Chandrakasan, A.P. Self-powered signal processing using vibration-based power generation. IEEE J. Solid-State Circuit. 1998, 33, 687.

93. Stephen, B.; White, N. Chapter 4 Kinetic Energy Harvesting. In Energy Harvesting for Autonomous Systems; Artech House: Norwood, MA, USA, 2010; pp. 90-131.

94. Manoli, Y. Energy harvesting-from devices to systems. In Proceedings of the ESSCIRC, Seville, Spain, 14-16 September 2010.

95. Khan, S.F.U. Vibration-based Electromagnetic Energy Harvesters for MEMS Applications; Ph.D. Thesis, The University of British Columbia: Vancouver, Canada, April 2011, p. 157.

96. Beeby, S.; Tudor, M.; White, N. Energy harvesting vibration sources for microsystems applications. Measurem. Sci. Technol. 2006, 17, R175-R195.

97. Trainer, M. Kelvin and piezoelectricity. European J. Phys. 2003, 24, 535-542.

98. Yang, J. Chapter one, Sec. 2.2 Piezoelectric effect. In An introduction to the theory of piezoelectricity; Springer: Boston, MA, USA, 2005; pp. 10-11.

99. Woias, P. Micro energy harvesting as a core technology for energy-autonomous embedded systems. In Proceedings of PowerMEMS 2011, Seoul, Korea, 15-18 November 2011.

100. Chew, Z.; Li, L. Design and characterisation of a piezoelectric scavenging device with multiple resonant frequencies. Sens. Actuators A Phys. 2010, 162, 82.

101. Kok, S.L. Design, Fabrication and Characterisation of Freestanding Thick-Film Piezoelectric Cantilevers for Energy Harvesting. Ph.D. Thesis, University of Southampton: Southampton, January 2010, p. 237.

102. Advanced Cerametrics, Piezo Fibre Composite transducer. Available online: http://www.advancedcerametrics.com/ (accessed on 1 October 2010).

103. Bogue, R. Energy harvesting and wireless sensors: A review of recent developments. Sens. Rev. 2009, 29, 194-199. 
104. Churchill, D.L.H.; Michael, J.T.; Christopher, P.; Arms, S.W. Strain energy harvesting for wireless sensor networks. In Proceedings of the Smart Structures and Materials 2003: Smart Electronics, MEMS, BioMEMS, and Nanotechnology, San Diego, CA, USA, 2 March 2003.

105. Steven, C.P.T.; Arms, W.; David, L.C. Energy Harvesting Wireless Sensors for Helicopter Damage Tracking. In Proceedings of AHS International Forum 62, HUMS III session, Phoenix, AZ, USA, 11 May 2006.

106. Yang, B.; Lee, C.; Kee, W.L.; Lim, S.P. Hybrid energy harvester based on piezoelectric and electromagnetic mechanisms. J. Micro/Nanolithogr. MEMS MOEMS 2010, 9, 023002-023002-10.

107. Qin, Y.; Wang, X.; Wang, Z.L. Microfibre-nanowire hybrid structure for energy scavenging. Nature 2008, 451, 809.

108. Vinod, R.C.; Prasad, M.G.; Fisher, F.T. A coupled piezoelectric-electromagnetic energy harvesting technique for achieving increased power output through damping matching. Smart Mater. Struct. 2009, 18, 11.

109. Kim, H.; Tadesse, Y.; Priya, S.; Priya, S.; Inman, D.J. Piezoelectric Energy Harvesting Energy Harvesting Technologies; Springer: New York, NY, USA, 2009; p. 3.

110. Qi, Y.; Jafferis, N.T.; Lyons, K.; Lee, C.M.; Ahmad, H.; McAlpine, M.C. Piezoelectric Ribbons Printed onto Rubber for Flexible Energy Conversion. Nano Lett. 2010, 10, 524.

111. Min, G. Chapter 5: Thermoelectric Energy Harvesting. In Energy Harvesting for Autonomous Systems; Artech House: Norwood, MA, USA, 2010; pp. 13-155.

112. Shu, Y.-C. Chapter 3: Performance Evaluation of Vibration-Based Piezoelectric Energy Scavengers. In Energy Harvesting Technologies; Springer: New York, NY, USA, 2009; pp. 79-105.

113. Pereyma, M. Overview of the Modern State of the Vibration Energy Harvesting Devices. In Proceedings of the International Conference on Perspective Technologies and Methods in MEMS Design, Liviv, Polyana, Ukraine, 23-26 May 2007; pp. 107-112.

114. Mitcheson, P.D.; Reilly, E.K.; Toh, T.; Wright, P.K.; Yeatman, E.M. Performance limits of the three MEMS inertial energy generator transduction types. J. Micromech. Microeng. 2007, 17, S211-S216.

115. IEEE Standard on Piezoelectricity; ANSI/IEEE Std 176-1987, IEEE: NY, USA, 1988.

116. Steve, C.L.Y. Low Power Wireless Sensor Applications, in Department of Computer Science \& Engineering. Master Thesis, The Chinese University of Hong Kong: Hong Kong, June 2004; p. 94.

117. Hu, J.; Yuan, F.-G.; Xu, F.; Huang, A.Q. An optimal design of magnetostrictive material (MsM) based energy harvester. In Proceedings of the Sensors and Smart Structures Technologies for Civil, Mechanical, and Aerospace Systems 2010, San Diego, CA, USA, 31 March 2010.

118. Cammarano, A.; Burrow, S.G.; Barton, D.A.W.; Carrella, A.; Clare, L.R. Tuning a resonant energy harvester using a generalized electrical load. Smart Mater. Struct. 2010, 19, 1-7.

119. Clare, L.R.; Burrow, S.G. Power conditioning for energy harvesting. In Proceedings of the Active and Passive Smart Structures and Integrated Systems 2008, San Diego, CA, USA, 18 April 2008.

120. Ramond, A.; Sanchez, M.; Li, K.; Durou, H.; Jammes, B.; Rossi, C. A single inductor dido converter with ultra low power mppt and thin-film lipon battery for piezoelectric energy 
harvesting and management. In Proceedings of the PowerMEMS, Leuven, Belgium, 30 November-3 December 2010.

121. Guan, M.J.; Liao, W.H. Characteristics of Energy Storage Devices in Piezoelectric Energy Harvesting Systems. J. Intell. Mater. Syst. Struct. 2008, 19, 671-680.

122. Sodano, H.A.; Inman, D.J.; Park, G. Comparison of Piezoelectric Energy Harvesting Devices for Recharging Batteries. J. Intell. Mater. Syst. Struct. 2005, 16, 799-807.

123. Squires, D. Overview of Storage Technologies for Energy Harvesting Applications. In Proceedings of the the First Annual Workshop on Micro Power Techologies, San Jose, CA, USA, 22 October 2009.

124. Ludvigsen, K. Porsche: Excellence Was Expected; Bentley Publishers: MA, USA, 2003.

125. Herndl, T. Remote Sensing of Car Tire Pressure. In Energy Harvesting Systems: Principles, Modeling and Applications; Springer: New York, NY, USA, 2010; pp. 141-159.

126. Matsuzaki, R.; Todoroki, A. Wireless Monitoring of Automobile Tires for Intelligent Tires. Sensors 2008, 8, 8123-8138.

127. Lemon Law Center, TPMS Legislation. Available online: http://lemon.onecle.com/ fmvss-standard-no-138/ (accessed on 4 May 2012).

128. Blaney, J.R.; Benoit, W.L.; Brazeal, L.M. Blowout! Firestone's image restoration campaign. Public Relat. Rev. 2002, 28, 379.

129. Uemura, Y.; Oshita, S.; Konno, T.; Kobuna, T.; Yoshida, Y. Tire Pressure Warning System. SAE Techn. Papers 1985, paper No. 856044.

130. Qi, Z.; Bo, L.; Li, G.F. Design of tire pressure monitoring system based on resonance frequency method. In Proceedings of the IEEE/ASME International Conference on Advanced Intelligent Mechatronics, Singapore, 14-17 July 2009; pp. 781-785.

131. Thiriez, K.K. Evaluation of indirect tire pressure monitoring systems using data from NCSA's tire pressure special study. US National Highway Traffic Safety Administration 2006, 259, 1-8.

132. APOLLO, Intelligent Tyre Systems-State of the Art and Potential Technologies; IST-2001-34372; Deliverable D7 2003.

133. Flatscher, M.; Dielacher, M.; Herndl, T.; Lentsch, T.; Matischek, R.; Prainsack, J.; Pribyl, W.; Theuss, H.; Weber, W. A Bulk Acoustic Wave (BAW) Based Transceiver for an In-Tire-Pressure Monitoring Sensor Node. IEEE J. Solid-State Circui. 2010, 45, 167.

134. Marsh, D. Safety check, wireless sensors eye tyre pressure. Available online: http://www.edn.com/file/15794-421537.pdf (accessed on 10 October 2010).

135. Lange, T.; Löhndorf, M.; Kvisterøy, T. Intelligent Low-Power Management and Concepts for Battery-less Direct Tire Pressure Monitoring Systems (TPMS). In Advanced Microsystems for Automotive Applications 2007, Springer: Berlin Heidelberg, Germany, 2007; pp. 237-249.

136. Becker, J.; Krueger, S.; Gessner, W. Tire Pressure Monitoring Systems - the New MEMS Based Safety Issue Advanced Microsystems for Automotive Applications Yearbook 2002; Springer: Berlin/Heidelberg, Germany, 2002; p. 243.

137. Cohen, P.; Valldorf, J.; Gessner, W. VisiTyre: A TPMS Solution Employing Directly Connected, 2-Wire Communication Channel to Achieve Highly Predictable and Reliable Performance. In Advanced Microsystems for Automotive Applications 2003; Springer: Berlin Heidelberg, Germany, 2003; pp. 203-213. 
138. Kurashige, T.; Kobane, S.; Takahashi, H.; Komatsu, S. Low Tire Pressure Warning Device (LTPWD). SAE Techn. Papers 1982, paper No. 820458.

139. Dixon, B.; Kalinin, V.; Beckley, J.; Lohr, R. A Second Generation In-Car Tire Pressure Monitoring System Based on Wireless Passive SAW Sensors. In Proceedings of the International Frequency Control Symposium and Exposition, Miami, FL, UA, 4-7 June 2006.

140. 140. Schimetta, G.; Dollinger, F.; Weigel, R. A wireless pressure-measurement system using a SAW hybrid sensor. IEEE Trans. Microw. Theory Techn. 2000, 48, 2730.

141. Deicke, F.; Graetz, H.; Fischer, W.-J. Analysis of Antennas for Sensor Tags Embedded in Tyres. In Proceedings of the 2009 5th European Workshop on RFID Systems and Technologies (RFID SysTech), Bremen, Germany, 16-17 June 2009; pp. 1-6.

142. Nabipoor, M.; Majlis, B.Y. A new passive telemetry LC pressure and temperature sensor optimized for TPMS. J. Phys. Confer. Series 2006, 34, 770-775.

143. Ho, I.H.; Jia-Min, C.; Hsiao-Chin, C.; Hung-Wei, C. A Battery-Less Tire Pressure Monitoring System. In Proceedings of the IEEE 69th Vehicular Technology Conference, Bercelona, Spain, 26-29 April 2009; pp 1-5.

144. Gruber, S.; Reinisch, H.; Unterassinger, H.; Wiessflecker, M.; Hofer, G.; Klamminger, M.; Pribyl, W.; Holweg, G. A passively powered BAW-based multi-standard in-tire identification and monitoring system. In Proceedings of the 2010 7th International Symposium on Communication Systems Networks and Digital Signal Processing (CSNDSP), Newcastle Upon Tyne, UK, 21-23 July 2010; pp. 300-304.

145. Grossmann, R. Wireless measurement of tire pressure with passive quartz sensors. In Proceedings of the Smart Structures and Materials 1999: Sensory Phenomena and Measurement Instrumentation for Smart Structures and Materials, Newport beach, CA, USA, 1-4 March 1999.

146. Flatscher, M.; Dielacher, M.; Prainsack, J.; Matischek, R.; Herndl, T.; Lentsch, T.; Pribyl, W. A bulk acoustic wave(BAW)-based sensor node for automotive wireless sensor networks. $e \& i$ Elektrotechnik und Informationstechnik 2008, 125, 143.

147. Vijay, K.; Varadan, K.; Jose, A.; Varadan, V.V. Design and development of passive MEMS-IDT sensors for continuous monitoring of tire pressure. In Proceedings of the Smart Electronics and MEMS II, Melbourne, Australia, 2001.

148. Makki, N.; Pop-Iliev, R. Battery-and wire-less tire pressure measurement systems (TPMS) sensor. Microsyst. Technol. 2012, 18, 1201-1212.

149. Makki, N.; Pop-Iliev, R. Piezoelectric power generation for sensor applications: design of a battery-less wireless tire pressure sensor. In Proceedings of the Smart Sensors, Actuators, and MEMS, Prague, Czech Republic, 18 April 2011.

150. Makki, N.; Pop-Iliev, R. Pneumatic tire-based piezoelectric power generation. In Proceedings of the Active and Passive Smart Structures and Integrated Systems 2011, San Diego, CA, USA, 7 March 2011.

151. Roundy, S. Energy Harvesting for Tire Pressure Monitoring Systems. In Proceedings of the First Annual Workshop on Micro Power Techologies, San Jose, California, CA, USA, 22 October 2009. 
152. Pinna, L. Vibration-Based Energy Scavenging for Power Autonomous Wireless Sensor Systems, in School of Science and Technology for Information and Knowledge, Ph.D. Thesis, University of Genoa: Genoa, Italy, February 2010; p. 141.

153. Frey, A.; Seidel, J.; Schreiter, M.; Kuehne, I. Piezoelectric MEMS energy harvesting module based on non-resonant excitation. In Proceedings of the 16th International Solid-State Sensors, Actuators and Microsystems Conference (TRANSDUCERS), Beijing, China, 5-6 June 2011, pp. 683-686.

154. Hu, Y.; Xu, C.; Zhang, Y.; Lin, L.; Snyder, R.L.; Wang, Z.L. A Nanogenerator for Energy Harvesting from a Rotating Tire and its Application as a Self-Powered Pressure/Speed Sensor. Adv. Mater. 2011, 23, 4068-4071.

155. Gu, L.; Livermore, C. Pendulum-driven passive self-tuning energy harvester for rotating applications. In Proceedings of the PowerMEMS workshop, Leuven, Belgium, 30 November-3 December 2010.

156. Vickery, P.E.; Nowell, A. Post assembly automatic adjustment of TPMS sensor preload; US 7798006 B2; 21 September 2010.

157. Franks, N.A.; Franks, M. System for accurately measuring and regulating air pressure in tires. US 7882731 B1; 8 February 2011.

158. Gao, Z.; Sham, M.-L.; Chung, C.H. Piezoelectric Module for Energy Harvesting, Such as in a Tire Pressure Monitoring System; US 2009/0211353 A1; 27 August 2009.

159. Blanchard, R.A. Self-Powered Sensor System for Monitoring Tire Pressure; US 2010/0164705 A1; 1 July 2010.

160. Bouchaud, J.; Dixon, R. Market Prospects for Micro Power Technologies, iSuppli. In Proceedings of the the First Annual Workshop on Micro Power Techologies, San Jose, CA, USA, 22 October 2009.

161. Haswell, S.W.F.G.; Holdsworth, P.R.; Bowles, S.J.; Smart, D.M.; Garcia-Hernandez, M.J.; Chavez-Dominguez, J.A.; Turo-Peroy, A.; Salazar-Soler, J. Power generator. US 7504763 B2; 17 March 2009.

162. Acts adopted by bodies created by international agreements. In Official Journal of the European Union: 26 November 2010; pp. L 310/18-L 310/40.

163. Tuononen, A.J. Optical position detection to measure tyre carcass deflections. Veh. Syst. Dyn. 2008, 46, 471-481.

164. Anghelache, G.; Moisescu, R.; Sorohan, S.; Buretea, D. Measuring system for investigation of tri-axial stress distribution across the tyre-road contact patch. Measurement 2011, 44, 559-568.

(C) 2014 by the authors; licensee MDPI, Basel, Switzerland. This article is an open access article distributed under the terms and conditions of the Creative Commons Attribution license (http://creativecommons.org/licenses/by/3.0/). 